INSPECTING THE MECHANISM:

LEVERAGE AND THE GREAT RECESSION IN THE EUROZONE

Philippe Martin

Thomas Philippon

WORKING PAPER 20572 
NBER WORKING PAPER SERIES

\title{
INSPECTING THE MECHANISM: \\ LEVERAGE AND THE GREAT RECESSION IN THE EUROZONE
}

\author{
Philippe Martin \\ Thomas Philippon
}

Working Paper 20572

http://www.nber.org/papers/w20572

\author{
NATIONAL BUREAU OF ECONOMIC RESEARCH \\ 1050 Massachusetts Avenue \\ Cambridge, MA 02138 \\ October 2014
}

We thank Pierre Olivier Gourinchas, Nobu Kiyotaki, Fiorella De Fiore, Emi Nakamura, Vania Stavrakeva, Ivan Werning and Philip Lane for their discussions, as well as Mark Aguiar, Olivier Blanchard, Ariel Burstein, Giovanni Dell'Arricia, Gita Gopinath, Gianluca Violante, Caterina Mendicino, Mark Gertler, Virgiliu Midrigan and seminar participants at AEA, NY Fed, NYU, Harvard, Berkeley, Oxford, IMF, Warwick, Maryland, TSE, PSE, Banque de France, CREI, ECB, Warwick, ESSIM-CEPR, the NBER IF and the NBER EFG for their comments. Joseba Martinez provided outstanding research assistance. We thank the Fondation Banque de France for financial support. Philippe Martin is also grateful to the Banque de France Sciences Po partnership for its financial support. The views expressed herein are those of the authors and do not necessarily reflect the views of the National Bureau of Economic Research.

NBER working papers are circulated for discussion and comment purposes. They have not been peerreviewed or been subject to the review by the NBER Board of Directors that accompanies official NBER publications.

(C) 2014 by Philippe Martin and Thomas Philippon. All rights reserved. Short sections of text, not to exceed two paragraphs, may be quoted without explicit permission provided that full credit, including (C) notice, is given to the source. 
Inspecting the Mechanism: Leverage and the Great Recession in the Eurozone

Philippe Martin and Thomas Philippon

NBER Working Paper No. 20572

October 2014, Revised May 2015

JEL No. E2,E3,E4,E6,F3,F4

\begin{abstract}
We provide a comprehensive account of the dynamics of eurozone countries from 2000 to 2012 . We analyze private leverage, fiscal policy, labor costs and interest rates and we propose a strategy to separate the impact of credit cycles, excessive government spending, and sudden stops. We then ask how eurozone countries would have fared with different policies. We find that most countries could have stabilized their employment if they had followed more conservative fiscal policies during the boom. Macro-prudential policies and an early intervention by the central bank to prevent market segmentation would also have significantly reduced the recession.
\end{abstract}

\author{
Philippe Martin \\ Sciences Po \\ Department of Economics \\ 28 rue des Saints Peres \\ 75007 Paris \\ France \\ and CEPR \\ philippe.martin@sciencespo.fr \\ Thomas Philippon \\ New York University \\ Stern School of Business \\ 44 West 4th Street, Suite 9-190 \\ New York, NY 10012-1126 \\ and NBER \\ tphilipp@stern.nyu.edu
}




\section{Introduction}

The lesson to be learned from the crisis is that a currency union needs ironclad budget discipline to avert a boom-and-bust cycle in the first place. Hans Werner Sinn (2010) On the eve of the crisis (Spain) had low debt and a budget surplus. Unfortunately, it also had an enormous housing bubble, a bubble made possible in large part by huge loans from German banks to their Spanish counterparts. Paul Krugman (2012)

The situation of Spain is reminiscent of the situation of emerging economies that have to borrow in a foreign currency...they can suddenly be confronted with a "sudden stop" when capital inflows suddenly stop leading to a liquidity crisis. Paul de Grauwe (2012) Countries which lost competitiveness prior to the crisis experienced the lowest growth after the crisis. Lorenzo Bini Smaghi (2013)

These quotes illustrate a persistent disagreement about the best way to interpret the eurozone crisis. Some argue that the crisis stems from a lack of fiscal discipline, some emphasize excessive private leverage, while others focus on sudden stops or competitiveness divergence due to fixed exchange rates. Most observers understand that all these factors have played a role, but do not offer a way to quantify their respective importance. In this context it is difficult to frame policy prescriptions on macroeconomic policies and on reforms of the eurozone. Moreover, given the scale of the crisis, understanding the dynamics of the eurozone is one of the major challenge for macroeconomics today. In this context, we propose a quantitative model to understand the dynamics of countries within the eurozone.

The ultimate goal of this paper is to perform counterfactual experiments. For instance, we want to understand what would have happened to a particular country if it had run a different fiscal policy during the boom years, or if the eurozone had been able to prevent sudden stops. Our contribution is to propose a model and an identification strategy to answer these questions. Needless to say, this is a difficult task that requires several steps: (i) specify a model and collect the data; (ii) find an identification strategy; (iii) run counterfactual experiments.

We analyze the dynamics of private debt, fiscal policy, and funding costs in a collection of small open economies within a monetary union. Each economy has an independent fiscal authority and is populated by patient and impatient agents. Impatient agents borrow from patient agents at home and abroad, and are subject to time-varying borrowing limits. Governments borrow, tax, and spend. Funding costs are linked to private and public debt sustainability. Nominal wages adjust slowly and changes in nominal expenditures affect employment.

Business Cycle Accounting in the Eurozone Our first contribution is to perform a business cycle accounting exercise for the eurozone. We show that the parsimonious model outlined above does a fairly good job at replicating the dynamics of each country from 2000 to 2012. It is important to emphasize that we focus on the dynamics of each country relative to the eurozone average. This 
approach helps us identify the model by netting out some aspects of monetary policy and exchange rate fluctuations. For instance, we seek to explain relative employment and inflation in Spain, but not aggregate employment and inflation in the eurozone. We show that, given the relative paths of private debt, government spending and interest rates from 2000 to 2012, the model predicts fairly well the relative paths for GDP, employment, inflation, net exports, etc. All the driving variables are directly observable and the model has very few degrees of freedom.

It is clear, however, that this exercise cannot tell us what caused the recessions in different countries. Private debt, fiscal policy and funding costs are endogenous equilibrium objects, and we want instead to identify "sudden stop" shocks, "private lending" shocks, and "discretionary" fiscal choices. All these shocks affect interest rates, debt dynamics, and via general equilibrium effects and policy responses, output and employment. We therefore need an identification strategy.

Identification Strategy The strategy we propose is based on a combination of functional restrictions, instrumental variable regressions, and the use of a control group.

We first specify the decision rule that pins down government spending as a function of the state of the economy. We assume that the government seeks to stabilize employment near its natural rate, cuts spending in response to an increase in borrowing costs, and is subject to a country-specific spending bias. The first two components of the decision rule are the same in all countries. The third component contains one parameter per country, which is the bias needed to reconcile actual and predicted average spending during the boom. We estimate a small (essentially zero) "political economy" bias in several countries, such as Germany and Portugal, and a large one in some other countries, such as Greece for instance.

We then model sudden stops as a common risk factor that increases after 2008, and we show that it materializes in countries with high public and private debts, including implicit liabilities linked to bank recapitalization costs. We use instrumental variables to estimate the impact of public and private debts on the economy's cost of funds, assuming that governments did not anticipate that a crisis would come at the end of the boom.

The last identification issue is the most difficult. We need to ascertain how the sudden stop affects the dynamics of private debt. This is complicated because private deleveraging can happen even without sudden stop and because we are not willing to impose the same restrictions regarding functional forms and anticipations on private agents as we impose on governments. Our key idea instead is to use the United States as a control group. The U.S. experience is both similar and different from the eurozone experience. A salient feature of the Great Recession in both monetary unions is that regions that have experienced large swings in private borrowing have also experienced large declines in employment and output. Figure (1) shows that the change in households' debt-toincome ratios during the boom (2003-2007) predicts the change in employment during the private credit crunch (2007-2010). ${ }^{1}$ The important point for our purpose is that, until 2010, the American

\footnotetext{
${ }^{1}$ The figure is for the largest US states and eurozone countries. State level household debt for the US comes from the Federal Reserve Bank of New York, see Midrigan and Philippon (2010). The mean changes are different since the private boom/bust cycle is a bit larger in the U.S., but this is not an issue for us since, as explained earlier, we
} 
and European experiences look strikingly similar. In both cases, there is a significant dispersion of leverage and employment, a very good fit, and (almost) the same slopes. This suggests similar structural parameters governing the endogenous propagation mechanism.

Figure 1: First Stage of the Great Recession: Household Borrowing predicts Employment Bust in the US and the EZ

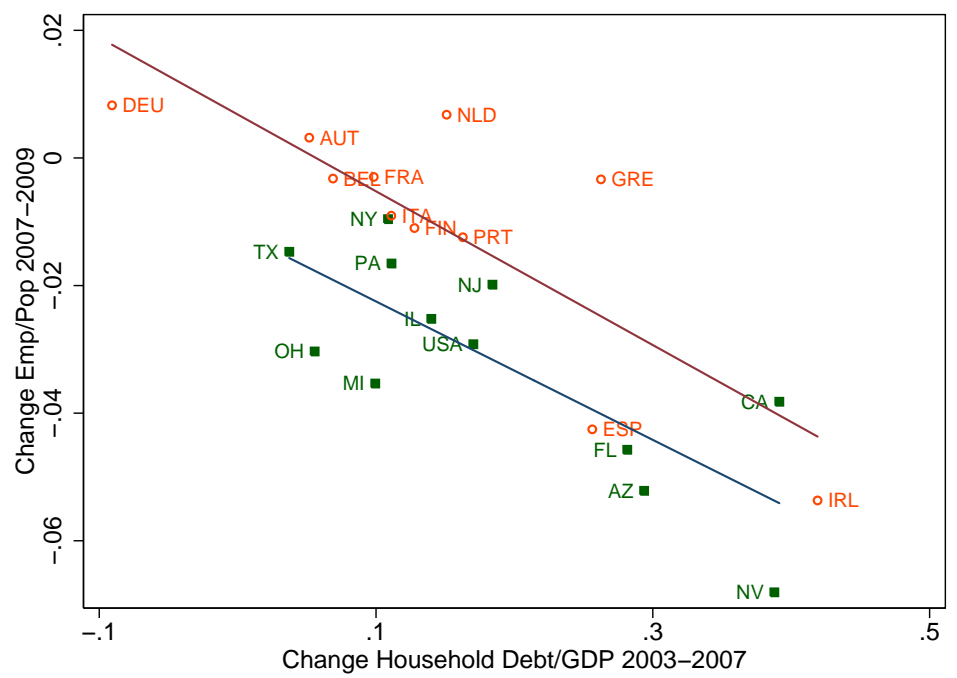

A significant difference between the two regions appears only after 2010 when the eurozone experiences sudden stops, financial fragmentation, and sovereign debt crises coupled with the risk of a breakup of the currency union. ${ }^{2}$ States within the U.S. do not experience sudden stops, but they reduce their private leverage nonetheless. Our identification strategy is then to use actual private debt dynamics across the U.S. to construct predicted debt series across eurozone countries. We argue that these are the private debt dynamics that would prevail in the eurozone without financial fragmentation. Importantly, these predicted debt series are far from constant and failure to recognize this fact would lead to severe biases in the estimations of the true causes of the eurozone crisis.

Structural Model and Counter-Factual Experiments Our structural model therefore features endogenous private debt, fiscal policy and cost of funds. The exogenous driving forces are a time varying risk of sudden stop (one time series), country specific political economy biases (one number per country), and the predicted private debt series (one time series per country). We show that this structural model fits the data well. Given the exogenous driving forces, the model predicts fairly well the relative paths of GDP, employment, inflation, net exports, public debt and private

focus on dynamics relative to the average.

${ }^{2}$ Sudden stops were frequent in the 19 th and 20 th centuries but we do not know of any other historical example of a sudden stop inside a monetary union. See Accominotti and Eichengreen (2013). 
debt from 2000 to 2012. This is a demanding exercise since we ask the model to predict the booms, the turning points and the busts for all the series and all the countries.

The critical advantage of the structural model - compared to the model that takes as given the paths of private debt, government spending and spreads, as explained above - is that we can use the structural model to perform counterfactual experiments. We perform four such experiments.

We first ask how countries would have fared if they had followed more conservative fiscal policies during the boom. To do so, we shut down the "political economy spending bias" of the structural model. We find that such policies lead to lower spreads and less need for fiscal austerity during the bust. Periphery countries partially stabilize their employment. This is especially true for Greece, and to a lesser extent for Ireland and Spain. For Ireland, however, this more conservative policy requires buying back the entire stock of public debt, which suggests that fiscal policy is unlikely to be enough as a stabilization tool against a large credit boom.

We then ask how these countries would have fared if they had conducted macro-prudential policies to limit the increase in private debt. This policy stabilizes private demand and therefore employment, and it reduces the need for bank recapitalization, leading to lower spreads and more room for countercyclical fiscal policy, especially in Ireland. Our experiment also uncovers a new interaction between macro-prudential and fiscal policies. A biased government substitutes public debt for private debt in response to restrictive macro-prudential policy, thereby undoing some of the macro-prudential benefits. This suggests a complementarity between fiscal rules and macroprudential rules.

In a third counterfactual experiment, we assume that the European Central Bank's OMT program (and Mario Draghi's "Whatever it takes" speech) is announced in 2008 rather than in 2012. This reduces the risk of a breakup of the eurozone, prevents the increase in spreads, and allows the four periphery countries to stabilize employment after 2010. Interestingly, the counter-factual employment dynamics across the eurozone then look similar to the observed dynamics across the United States.

In our last counterfactual, we let countries engineer a $10 \%$ fiscal devaluation in 2009. This generates a boom in exports, a shorter and milder recession, and a successful fiscal adjustment with a lower public debt in 2012. Overall, our results are consistent with many policy makers' beliefs about the crisis, but we are the first to formalize and quantify them.

Literature review Our paper is most directly related to three lines of research: macro-economic models with credit frictions, in particular that of Eggertsson and Krugman (2012); open-economy models with interest rates shocks, as in Neumeyer and Perri (2005); and analyses of the eurozone crisis such as Lane (2012) for instance.

Kiyotaki and Moore (1997), Bernanke et al. (1999) and Gertler and Kiyotaki (2010) consider credit constraints that limit corporate investment, while we put more emphasis on household credit, as Mian and Sufi (2012), Midrigan and Philippon (2010) and Eggertsson and Krugman (2012). This difference matters mostly when we fit the model with cross-sectional data. A striking feature of 
the data is the strong correlation between household leverage and employment at the micro-level. Mian and Sufi (2012) show that differences in household debt overhang explains why unemployment is higher in some counties than in others. These facts are not easily explained by a "local lending channel" or by credit constraints that operate only at the firm level, presumably because business lending is not very localized in the U.S. ${ }^{3}$

The literature on sudden stops in emerging markets focuses on the rapid imposition of an external credit constraint, and usually emphasizes Fisherian amplification when debts and incomes are denominated in different currencies (see Christiano and Roldos 2004; Chari et al. 2005; Mendoza and Smith 2006; Mendoza, 2010; Korinek and Mendoza 2013). The sudden stops themselves can be explained by multiple equilibria in international financial markets with transaction costs, as in Martin and Rey (2006). By contrast, we focus on countries that belong to a monetary union and our model integrates, for the first time to our knowledge, both domestic and external debt dynamics. This is critical for understanding the eurozone crisis since, as we have explained, private deleveraging would have created a recession even without an external credit constraint. In Neumeyer and Perri (2005) interest rates shocks, either exogenous or induced by productivity shocks, generate sudden stops and current account reversals because they induce a working capital shortage. In our model, the increase in interest rates generates a demand shock through a fall in private and public expenditures.

Our business cycle accounting exercise is similar in spirit to the work of Chari et al. (2007) but we emphasize different shocks. While most of the sudden stop literature has emphasized credit constraints, Gopinath (2004) and Aguiar and Gopinath (2007) have focused on TFP shocks. In Aguiar and Gopinath (2007) a negative shock to trend growth leads to a fall in consumption and an increase in the trade balance. ${ }^{4}$ TFP shocks are certainly important in emerging markets, but they do not seem to explain the dynamics of euro area countries during the great recession. Countries hit by sudden stops (Greece, Ireland, Italy, Spain, Portugal) do not experience the largest reversals in trend TFP growth, and there is no correlation between changes in TFP growth and employment losses during the recession (see figure (21) in Appendix B.1). In fact, the only country that shows signs of TFP growth during the boom years is Greece, but the reliability of these numbers is questionable.

Our paper is related to the literature on sovereign credit risk (see Eaton and Gersovitz 1982; Arellano 2008; Mendoza and Yue 2012) but we do not actually model strategic default decisions. We focus instead on how sovereign default risk affects the real economy. Corsetti et al. (2013) model

\footnotetext{
${ }^{3}$ Mian and Sufi (2010) find that the predictive power of household borrowing remains the same in counties dominated by national banks. It is also well known that businesses entered the recession with historically strong balance sheets and were able to draw on existing credit lines, as shown by Ivashina and Scharfstein (2008). On the other hand, our model is perfectly consistent with firm level credit constraints in addition to household level credit constraints, as discussed recently by Giroud and Mueller (2015). Our approach is also consistent with the lending constraints view of Justiniano et al. (2014).

${ }^{4}$ Gopinath (2004) proposes a model with a search friction to generate asymmetric responses to symmetric shocks. A search friction in foreign investors' entry decision into emerging markets creates an asymmetry in the adjustment process of the economy: An increase in traded sector productivity raises GDP on impact, and it continues to grow to a higher long-run level. On the other hand, a decline in traded sector productivity causes GDP to contract in the short run by more than it does in the long-run. Aguiar and Gopinath (2007) do not study the response of the labor market but it is well known that income effects tend move consumption and hours in opposite directions.
} 
such a "sovereign risk channel" through which sovereign default risk raises the private sector cost of funds. A high cost of funds forces the government to cut spending and our model is qualitatively and quantitatively consistent with the recent research on fiscal multipliers at the regional level (see Nakamura and Steinsson, 2014; Farhi and Werning 2013).

The papers by Lane (2012) and Shambaugh (2012) provide a thorough description of the four dimensions of the eurozone crisis: public debt, private debt, sudden stop and competitiveness. The specific role of the boom/bust cycle in capital flows is analyzed by Lane (2013) while Gourinchas and Obstfeld (2012) show that domestic credit expansion is the most robust predictor of financial crises. Battistini et al. (2014) argue that the perceived risk of a eurozone breakup is a key driver of financial fragmentation during the crisis. Schmitt-Grohe and Uribe (2012) emphasize the role of downward wage rigidity. Some papers also compare and describe the specific circumstances of individual countries. Fernández Villaverde et al. (2013) argue that loose financing conditions and capital inflows following the creation of the euro relaxed the pressure for reforms in the four periphery countries. Reis (2013) argues that capital misallocation explains the low growth of Portugal between 2000 and 2007. Whelan (2014) stresses the role of cheap credit and lax banking regulation in Ireland, and Cunat and Guadalupe (2009) analyzes the lending behavior of the Spanish Cajas in the run up to the crisis. While our model cannot do justice to the specificities of every single country, it nonetheless gives an interpretation of the crisis that is consistent with the views expressed in these various papers.

The remaining of the paper is organized as follows. In Section 2 we present the model and in section 3 we analyze its dynamic properties. Section 4 compares the predictions of the reduced form model to the data. In Section 5 we estimate the structural relations between private leverage, fiscal policy and sudden stops. The structural model is used to conduct our counterfactual experiments in section 6. Section 7 concludes. There are also several Appendices presenting the data sources, the various adjustments that need to be made to the raw data, the details of the model, and the simulations.

\section{Model}

We model a currency union with several regions. We follow Gali and Monacelli (2008) and study a small open economy that trades with other regions. Each region $j$ produces a tradable domestic good and is populated by households who consume the domestic good and a basket of foreign goods. Following Mankiw (2000) and more recently Eggertsson and Krugman (2012), we assume that households are heterogenous in their degree of time preference. More precisely, in region $j$, there is a fraction $\chi_{j}$ of impatient households, and $1-\chi_{j}$ of patient ones. Patient households (indexed by $i=s$ for savers) have a higher discount factor than borrowers (indexed by $i=b$ for

borrowers): $\beta \equiv \beta_{s}>\beta_{b}$. Saving and borrowing are measured in units of the common currency (euros). 


\subsection{Within period trade and production.}

Consider household $i$ in region $j$ at time $t$. Within period, all households have the same $\log$ preferences over the consumption of home goods $(h)$, foreign goods $(f)$, and labor supply:

$$
u_{i, j, t}=\alpha_{j} \log \left(\frac{C_{i, j, t}^{h}}{\alpha_{j}}\right)+\left(1-\alpha_{j}\right) \log \left(\frac{C_{i, j, t}^{f}}{1-\alpha_{j}}\right)-\nu\left(N_{i, j, t}\right)
$$

With these preferences, households of region $j$ spend a fraction $\alpha_{j}$ of their income on home goods, and $1-\alpha_{j}$ on foreign goods. The parameter $\alpha_{j}$ measures how closed the economy is, because of home bias in preferences or trade costs. The demand functions are then:

$$
\begin{aligned}
P_{j, t}^{h} C_{i, j, t}^{h} & =\alpha_{j} X_{i, j, t}, \\
P_{t}^{f} C_{i, j, t}^{f} & =\left(1-\alpha_{j}\right) X_{i, j, t} .
\end{aligned}
$$

where

$$
X_{i, j, t} \equiv P_{j, t}^{h} C_{i, j, t}^{h}+P_{t}^{f} C_{i, j, t}^{f}
$$

measures total spending by household $i$ in region $j$ in period $t, P_{j, t}^{h}$ is the price of home goods in country $j$ and $P_{t}^{f}$ is the price index of foreign goods. This gives the indirect utility

$$
U\left(X_{i, j, t}, P_{j, t}\right)=\log \left(X_{i, j, t}\right)-\log \bar{P}_{j, t}-\nu\left(N_{i, j, t}\right)
$$

where the CPI of country $j$ is $\log \bar{P}_{j, t}=\alpha_{j} \log P_{j, t}^{h}+\left(1-\alpha_{j}\right) \log P_{j, t}^{f}$, the PPI is $P_{j, t}^{h}$, and the terms of trade are $\frac{P_{t}^{f}}{P_{j, t}^{h}}$. Foreign demand for the home good also has a unit elasticity with respect to export price $P_{j, t}^{h}$. Production is linear in labor $N_{j, t}$ and competitive, so

$$
P_{j, t}^{h}=W_{j, t}
$$

Market clearing in the goods market requires

$$
N_{j, t}=\chi_{j} C_{b, j, t}^{h}+\left(1-\chi_{j}\right) C_{s, j, t}^{h}+\frac{F_{j, t}}{P_{j, t}^{h}}+\frac{G_{j, t}}{P_{j, t}^{h}},
$$

where $F_{j, t}$ is foreign demand and $G_{j, t}$ are nominal government expenditures. Note that we assume that the government spends only on domestic goods. Define nominal gross domestic product as

$$
Y_{j, t} \equiv W_{j, t} N_{j, t}
$$

and total private expenditures as

$$
X_{j, t} \equiv \chi_{j} X_{b, j, t}+\left(1-\chi_{j}\right) X_{s, j, t} .
$$


It is useful to write the market clearing condition in nominal terms (in euros) as follows:

$$
Y_{j t}=\alpha_{j} X_{j, t}+F_{j, t}+G_{j, t}
$$

\subsection{Inter-temporal budget constraints}

Let $B_{j, t}$ be the face value of the debt issued in period $t-1$ by impatient households and due in period $t$. Each household supplies labor at the prevailing wage and receives wage income net of taxes $\left(1-\tau_{j, t}\right) W_{j, t} N_{j, t}$. They also receive transfers from the government $Z_{j, t}$. It will be convenient to define disposable income (after tax and transfers but before interest payments) as

$$
\tilde{Y}_{j, t} \equiv\left(1-\tau_{j, t}\right) Y_{j, t}+Z_{j, t}
$$

The budget constraint of impatient households in country $j$ is then

$$
\frac{B_{j, t+1}}{1+r_{j, t}}+\tilde{Y}_{j, t}=X_{b, j, t}+B_{j, t}
$$

where $r_{j, t}$ is the nominal cost of funds between $t$ and $t+1$. Notice that the budget constraint is written without the possibility of default by the borrower. In such a case, and without taking into account issues of market liquidity, the cost of fund is the same as the interest rate. When we discuss the model, we therefore refer to $r_{j, t}$ as the interest rate. But when we turn to the data, it is obviously critical to remember that $r_{j, t}$ is really meant to capture the cost of funds. We assume that interest rates are time-varying and potentially country-specific. Borrowing is subject to the exogenous limit $B_{j, t}^{h}$ :

$$
B_{j, t} \leq B_{j, t}^{h}
$$

The savers' budget constraint is:

$$
S_{j, t}+\tilde{Y}_{j, t}=X_{s, j, t}+\frac{S_{j, t+1}}{1+r_{j, t}}
$$

so their Euler equation is

$$
\frac{1}{X_{s, j, t}}=\mathbb{E}_{t}\left[\frac{\beta\left(1+r_{j, t}\right)}{X_{s, j, t+1}}\right] .
$$

Note that financial markets clear in two ways in our model. Given that impatient agents are quantity constrained, interest rates do not affect their borrowing. For the patient agents, their saving is determined by the interest rate through the Euler equation.

The government budget constraint is:

$$
\frac{B_{j, t+1}^{g}}{1+r_{j, t}}+\tau_{j, t} Y_{j t}=G_{j, t}+Z_{j, t}+B_{j, t}^{g},
$$

where $B_{j, t}^{g}$ is public debt issued by government $j$ at time $t-1$. 


\subsection{Exports and foreign assets}

Nominal exports are $F_{j, t}$ and nominal imports are $\left(1-\alpha_{j}\right) X_{j, t}$ since the government does not buy imported goods while private agents spend a fraction $1-\alpha_{j}$ on foreign goods. So net exports are:

$$
E_{j, t}=F_{j, t}-\left(1-\alpha_{j}\right) X_{j, t}
$$

The net foreign asset position of the country at the end of period $t$, measured in market value, is:

$$
A_{j, t} \equiv\left(1-\chi_{j}\right) \frac{S_{j, t+1}}{1+r_{j, t}}-\chi_{j} \frac{B_{j, t+1}^{h}}{1+r_{j, t}}-\frac{B_{j, t+1}^{g}}{1+r_{j, t}} .
$$

Adding up the budget constraints, we have the spending equation

$$
X_{j, t}+G_{j, t}=Y_{j, t}+\chi_{j}\left(\frac{B_{j, t+1}^{h}}{1+r_{j, t}}-B_{j, t}^{h}\right)-\left(1-\chi_{j}\right)\left(\frac{S_{j, t+1}}{1+r_{j, t}}-S_{j, t}\right)+\frac{B_{j, t+1}^{g}}{1+r_{j, t}}-B_{j, t}^{g}
$$

Total spending (public and private) equals total income (nominal GDP) plus total net borrowing. If we combine with the market clearing condition (2), we get the current account condition

$$
C A_{j, t} \equiv A_{j, t}-A_{j, t-1}=E_{j, t}+r_{j, t-1} A_{j, t-1},
$$

It will often be convenient to rewrite (10) with disposable income as

$$
\left(1-\alpha_{j}\right) \tilde{Y}_{j, t}=\alpha_{j} \chi_{j}\left(\frac{B_{j, t+1}^{h}}{1+r_{j, t}}-B_{j, t}^{h}\right)-\alpha_{j}\left(1-\chi_{j}\right)\left(\frac{S_{j, t+1}}{1+r_{j, t}}-S_{j, t}\right)+F_{j, t}+\frac{B_{j, t+1}^{g}}{1+r_{j, t}}-B_{j, t}^{g}
$$

\subsection{Employment and Prices}

The system above completely pins down the dynamics of nominal variables: $Y_{j, t}, X_{i, j, t}$, etc. Employment (real output) is given by $N_{j, t}=\frac{Y_{j, t}}{W_{j, t}}$. We assume that wages are sticky and we ration the labor market uniformly across households. This assumption simplifies the analysis because we do not need to keep track separately of the labor income of patient and impatient households within a country. Not much changes if we relax this assumption, except that we lose some tractability. ${ }^{5}$ We

\footnotetext{
${ }^{5}$ In response to a negative shock, impatient households would try to work more. The prediction that hours increase more for credit constrained households appears to be counter-factual however. One can fix this by assuming a low elasticity of labor supply, which essentially boils down to assuming that hours worked are rationed uniformly in response to slack in the labor market. Assuming that the elasticity of labor supply is small (near zero) also means that the natural rate does not depend on fiscal policy. In an extension we study the case where the natural rate is defined by the labor supply condition in the pseudo-steady state $\nu^{\prime}\left(n_{i}^{\star}\right)=\left(1-\tau_{j}\right) \frac{w_{j}}{x_{i, j}}$. We can then ration the labor market relative to their natural rate: $n_{i, j, t}=\frac{n_{i}^{\star}(\tau)}{\sum_{i} n_{i}^{\star}(\tau)} n_{j, t}$ where $n_{i}^{\star}(\tau)$ is the natural rate for household $i$ in country. This ensures consistency and convergence to the correct long run equilibrium. Steady state changes in the natural rate are quantitatively small, however, so the dynamics that we study are virtually unchanged. See Midrigan and Philippon (2010) for a discussion.
} 
assume the following Phillips curve

$$
\frac{W_{j, t}}{W_{j, t-1}}=\left(\frac{N_{j, t}}{\bar{N}_{j}}\right)^{\kappa}
$$

where $\bar{N}_{j}$ is the natural rate of employment. There are several points to discuss about this specification. We assume that the natural rate $\bar{N}_{j}$ is constant within country. This assumption will be rejected for Germany following the Hartz labor market reforms of 2003-2005 and our model will under-predict relative employment in Germany. Since our focus is on the crisis-hit countries we do not view this as an important problem. Another important assumption is that $\kappa$ is the same in all regions (i.e., we write $\kappa$ and not $\kappa_{j}$ ). This assumption is motivated by existing research, notably Montoya and Dohring (2011) who find fairly similar Phillips curve coefficients across eurozone countries. ${ }^{6}$ The same authors also find that the coefficients on inflation expectations are small relative to the backward-looking terms, which is why we omit the forward looking component for simplicity. ${ }^{7}$

\subsection{Discussion of the main modeling assumptions}

We have left out of the model all items that do not seem strictly necessary to identify the sources of the Great Recession across eurozone countries. ${ }^{8}$ The first version of the model had an explicit housing sector, but we decided to remove it to simplify the paper. Given the importance of housing in explaining the rise in household debt in Spain and Ireland, this choice deserves an explicit discussion. Obviously, we are not arguing that housing does not matter. It does, but the right question is exactly how, and more precisely, whether it matters independently of debt. In the class of models that we are considering, it turns out that housing matters (essentially) through debt. The reason can be understood from the work of Midrigan and Philippon (2010), where the debt constraint (4) is derived from a standard collateral constraint: $B_{j, t} \leq \eta Q_{j, t} H_{j, t}$, where $Q_{j, t}$ and $H_{j, t}$ are the price and quantity of housing, and $\eta$ is a parameter (which can be time varying if needed but this is immaterial for our discussion). If the supply of housing is fixed at the island level and $H_{j, t}=\bar{H}_{j}$ is an equilibrium condition, then the dynamics of this economy are exactly the same as the dynamics of an economy without housing where we exogenously impose $B_{j, t}^{h}=\eta Q_{j, t} \bar{H}_{j}$. It

\footnotetext{
${ }^{6}$ Montoya and Dohring (2011) find that the "estimates for the Member States are fairly well in line with the estimates for the euro area aggregate." For the main coefficient of interest, only two countries have estimates above or below one standard deviation of the euro area estimate. Importantly, there is no geographical pattern in the distribution of the coefficients, which we interpret as saying that the differences are probably just noise.

${ }^{7}$ This is not a strong assumption. As explained in the introduction, we focus on relative dynamics, i.e. the dynamics of a country relative to the eurozone average. For nominal wages, we write $W_{j, t}=W_{t}^{*} w_{j, t}$, where $W_{t}^{*}$ is a wage index for the eurozone, and $w_{j, t}$ is the country specific deviation from the average. We can assume that $W_{t}^{*}$ follows a standard Neo-Keynesian Phillips curve, as in Chapter 6 of Gali (2008). We do not dispute that changes in expected inflation via monetary policy signaling are important, but they are captured by $W_{t}^{*}$. For $w_{j, t}$ we find that the simple Phillips curve (12) does a good job matching the data. We have also estimated a more general model and found that the forward looking component does not improve the fit of the model.

${ }^{8} \mathrm{We}$ also ignore corporate investment but this is a lesser concern. First, for all firms (SMEs) that are credit constrained, we simply add their debts to our constrained households' debts since what matters is only the implied budget constraint. Other firms follow a q-equation similar to our Euler equation. There is only a quantitative difference in how we interpret the inter-temporal elasticity given that spending on durable goods can be more sensitive to interest rates than spending on non-durable goods.
} 
is indeed easy to check that both the first order conditions and the market clearing conditions are identical in the two economies. In that case, housing matters only through debt and we find it more transparent to model debt directly. The equivalence breaks down if the quantity of housing is endogenous because the labor market clearing condition must include construction workers. The downside of not including housing explicitly is therefore only that we might fail to capture the differential dynamics of hours worked in construction relative to hours worked in the rest of the economy. We argue that this is a small price to pay for a major simplification. ${ }^{9}$

Another simplification of our approach is that we model directly the (private and public) cost of funds, instead of modeling the details of each domestic financial system. It is important to emphasize that we will nonetheless take into account the feedback between sovereign debt and private credit, as well as the impact of bank recapitalizations on sovereign risk. These are the main channels of contagion that have been discussed in the context of the eurozone crisis. It is of course possible to study banking debt overhang in a fully specified model - as in Philippon and Schnabl (2013) for instance - but the economic consequences of debt overhang ultimately occur through the cost of funds. The structural equation we would end up estimating would be exactly the same as the one we are actually going to estimate, so our simulation would be exactly the same. The downside of not modeling banking explicitly is that we cannot answer micro questions about banking. We are able to quantify the benefits of limiting private credit expansion, but we are not able to say if this should be done via direct supervision, capital adequacy ratios, or liquidity regulations. These are important topics for future research.

\section{Dynamic Properties of the Model}

We now study the dynamics of a small open economy subject to shocks to the borrowing limit of impatient households $B_{j, t}^{h}$, to foreign demand $F_{j, t}$, to interest rates, and to fiscal policy. We present some simple impulse response functions to build intuition about the mechanics of the model. The details of the assumptions and policy functions used to compute these impulse responses are in Appendix A.6, while Martinez and Philippon (2014) provide a more theoretical discussion of the same framework, in particular regarding the behavior of savers. Here we only mention one insight that is useful to interpret the impulse responses. Saver's spending (in euros) reacts neither to $B_{j, t}^{h}$, nor to $G_{j, t}$ nor to $Z_{j, t}$, because shocks to these variables affect the path of disposable income but not the net present value (in euros) of disposable income. As a result, these shocks affect the expenditures of impatient agents (that are effectively hand-to-mouth) but not those of patient agents. Shocks to foreign demand or to interest rates, on the other hand, affect directly the expenditures of patient agents. These results rely on the log preferences of Cole and Obstfeld (1991). They are convenient because they allow us to solve the nominal side of the model (all

\footnotetext{
${ }^{9}$ Even with endogenous construction the dynamics of nominal spending are the same. The equivalence holds in our setup because we have two permanent types of households, patient and impatient. It would not necessarily hold in the more advanced setup of Kaplan and Violante (2011) where precautionary savings are important. In that case modeling housing separately could bring new insights, but this is far beyond the scope of this paper.
} 
variables in euros) independently of the Phillips curve, and we show later that they seem consistent with the data. Of course, even when nominal expenditures remain constant, real consumption changes because prices (equal to wages) react to changes in aggregate spending.

We now outline how we compute the dynamics of a country relative to the eurozone, and then we present the impulse responses to the various shocks.

\subsection{Scaling and Spreads}

We now define the country specific component of the variables of the model. We denote by "*" variables that are measured at the level of the monetary union as whole. We assume that the variance of interest rate shocks is small and we linearize the Euler equation (6) as $\mathbb{E}_{t}\left[X_{s, j, t+1}\right] \approx$ $\beta\left(1+r_{j, t}\right) X_{s, j, t}$. The equivalent equation for the monetary union as a whole is $\mathbb{E}_{t}\left[X_{s, t+1}^{*}\right] \approx$ $\beta\left(1+r_{t}^{*}\right) X_{s, t}^{*}$, where $r_{t}^{*}$ is the interest rate for the monetary union as a whole. We define the spread as:

$$
1+\rho_{j, t} \equiv \frac{1+r_{j, t}}{1+r_{t}^{*}}
$$

In Appendix A.1 we scale all our variables by aggregate (unconstrained) spending $X_{s, t}^{*}$. We define

$$
x_{s, j, t} \equiv \frac{X_{s, j, t}}{X_{s, t}^{*}} .
$$

We can then write the Euler equation as

$$
\mathbb{E}_{t}\left[x_{s, j, t+1}\right] \approx\left(1+\rho_{j, t}\right) x_{s, j, t} .
$$

From now on we work only with scaled variables (in lower case). For example, the patient budget constraint becomes:

$$
x_{s, j, t}+\frac{\beta}{1+\rho_{j, t}} s_{j, t+1}=s_{j, t}+\tilde{y}_{j, t} .
$$

Similarly the scaled Phillips curve is:

$$
\frac{w_{j, t}}{w_{j, t-1}}=1+\kappa\left(n_{j, t}-1\right)
$$

where $n_{j, t} \equiv \frac{N_{j, t} / \bar{N}_{j}}{N_{t}^{*} / N^{*}}$ is employment of country $j$ in deviation to its natural level and to the eurozone level.

Finally, we assume throughout the paper that $\mathbb{E}_{t}\left[f_{j, t+1}\right]=f_{j, t}$ so that the shocks to foreign demand are assumed to be permanent. In the empirical section we will assume that spreads follow an $\operatorname{AR}(1)$ process with persistence $\theta$, so $\mathbb{E}_{t}\left[\rho_{t+1}\right]=\theta \rho_{t}$. 


\subsection{Impulse responses to shocks}

Figure (2) in the main text, and (15), (16) and (17) in Appendix A.6 illustrate the impact of shocks to household debt $\left(b_{j, t}^{h}\right)$, public spending $\left(g_{j, t}\right)$, interest rates $\left(r_{j, t}\right)$ and foreign demand $\left(f_{j, t}\right){ }^{10}$

Figure 2: Private Credit Expansion
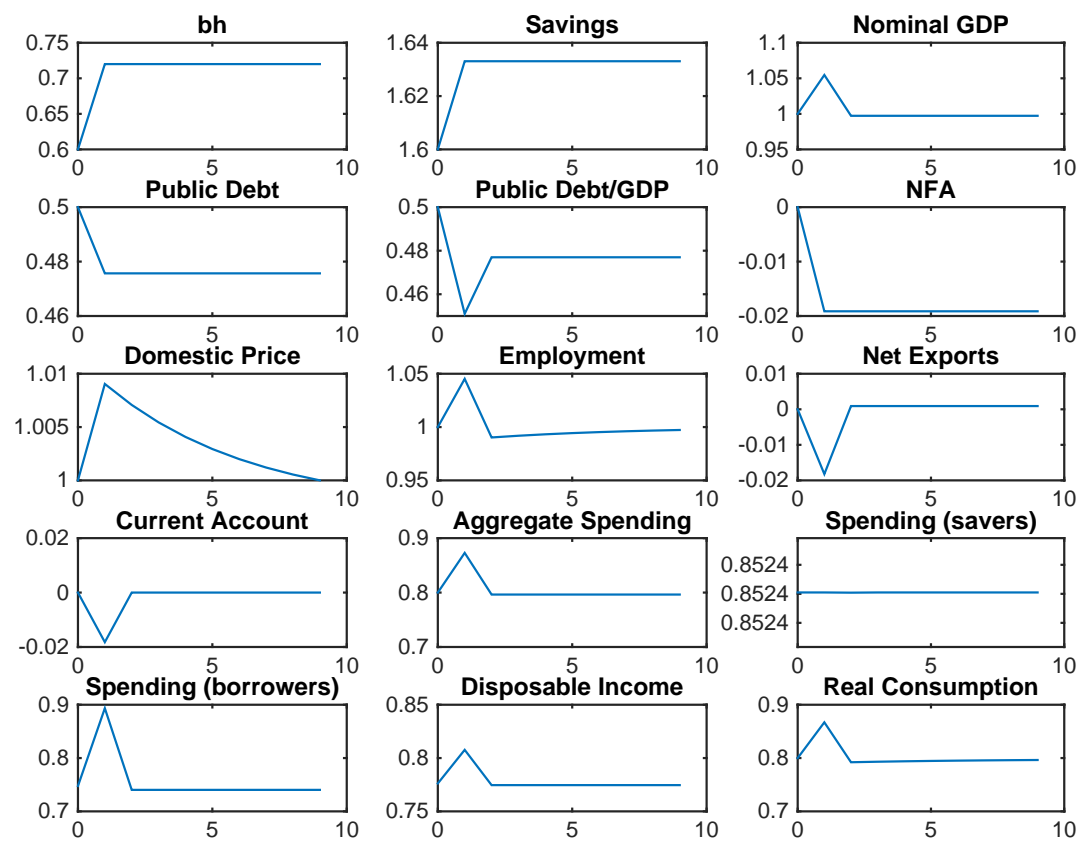

In figure (2) a permanent increase in the household debt enables impatient households to increase spending immediately while patient agents' expenditures do not move. This is because savers understand that the net present value (in euros) of their disposable income has not changed. For the government we assume a mildly counter-cyclical policy: $g$ and $z$ are set one period in advance, so when tax revenues go up, government debt falls. After the shock the policy simply stabilizes the level of debt. GDP follows aggregate spending, the current account turns negative, and employment goes up. The shock has a permanent impact on net foreign assets, but a temporary impact on employment and wages.

Figure (15) in Appendix A.6 shows the impact of a permanent increase in government spending. The consequences are similar to those of a private credit expansion, except of course that public debt increases. Impatient agents spend more because their income rises, while patient agents do

\footnotetext{
${ }^{10}$ The following parameters: $\alpha=0.75, \chi=0.5, r=0.05, \kappa=0.2, \tau=0.4$. Prices, wages and employment are normalized to unity at time $t=0$. The debt to income ratio is set at $60 \%$ for impatient households at time $t=0$, so that the household debt to income ratio is $30 \%$. The government debt to GDP ratio is set at $50 \%$ and the net foreign asset position over GDP at zero at time $t=0$. The shock is a $20 \%$ increase of the variable at $t=1$.
} 
not change their nominal spending and nominal interest rates in the small open economy do not change. Prices are permanently higher in the long run. Figures (2) and (15) show the response of the economy to two types of autonomous spending: that of constrained agents, and that of the government. The spending multipliers are increasing functions of $\alpha_{i}$ and $\chi_{i}$. A higher share of impatient agents in the economy implies that an increase in disposable income has a larger impact on aggregate expenditures. A higher share of spending on domestic goods reduces leakage through imports. Figure (16) in Appendix A.6 shows the response to an increase in domestic interest rates. ${ }^{11}$ It induces patient households to save more, so it reduces their expenditures and generates a recession (fall in nominal GDP and in employment) that forces impatient households to reduce their spending. Imports fall and the net foreign asset position improves. Because of lower tax revenues, the recession increases public debt. Figure (17) in the Appendix shows that an increase in foreign demand permanently increases nominal GDP. Spending of both patient and impatient households increase. The net foreign asset position improves. Public debt falls because of higher tax revenues.

\section{Reduced Form Model}

We simulate 11 eurozone countries from 2000 to 2012: Austria, Belgium, Germany, Spain, Finland, France, Greece, Ireland, Italy, Netherlands and Portugal and calibrate the shocks on the observed data. The data sources are described in Appendix B.1.

\subsection{Calibration}

The parameters used in the simulations are presented in Table (1). The discount factor (of patient households) and the Philipps curve parameter are standard. The country-specific parameters - the share of credit constrained households $\left(\chi_{j}\right)$ and the domestic share of consumption $\left(\alpha_{j}\right)$ - are shown on Figure (3).

\begin{tabular}{lcc}
\multicolumn{3}{c}{ Table 1: Parameters } \\
\hline Parameter Name & $\beta$ & Value \\
\hline Annual discount factor (patient) & $\alpha_{j}$ & country specific \\
Domestic share of consumption & $\chi_{j}$ & country specific \\
Share of credit constrained households & $\kappa$ & 0.3 \\
Phillips curve parameter & $\theta$ & 0.5 \\
Persistence of spreads shocks &
\end{tabular}

Trade: For the country specific domestic share of consumption, $\alpha_{j}$, we rely on Bussiere et al. (2011) who compute the total import content of consumption expenditures, including the value

\footnotetext{
${ }^{11}$ For these impulse response functions we assume an iid process for the spread shock. However, for simulations we use an AR process with the estimated persistence parameter $\theta$.
} 
of indirect imports. For our sample of countries the average implied domestic share in 2005 (the latest date in their study) is $72.7 \%$. The lowest is $66.4 \%$ for Belgium and the highest is $78.7 \%$ for Italy. For foreign demand $F_{j, t}$, given the absence of an intermediate goods sector in our model, we take the domestic value added that is associated with final consumption in the rest of the world, which corresponds to value added based exports. As detailed in Appendix B.1, we use the data from the OECD-WTO Trade in Value-Added (TiVA) initiative to measure this. The scaled valueadded based exports are shown in figure (26) in Appendix B.3. Finally, we take into account net EU transfers, which are the difference between EU spending in the country and the country contribution to the EU. In our model, such transfers play exactly the same role as foreign demand, so we add EU net transfers to exports in the goods market equation.

Figure 3: Share of credit constrained households $\left(\chi_{j}\right)$ and domestic share of consumption $\left(\alpha_{j}\right)$

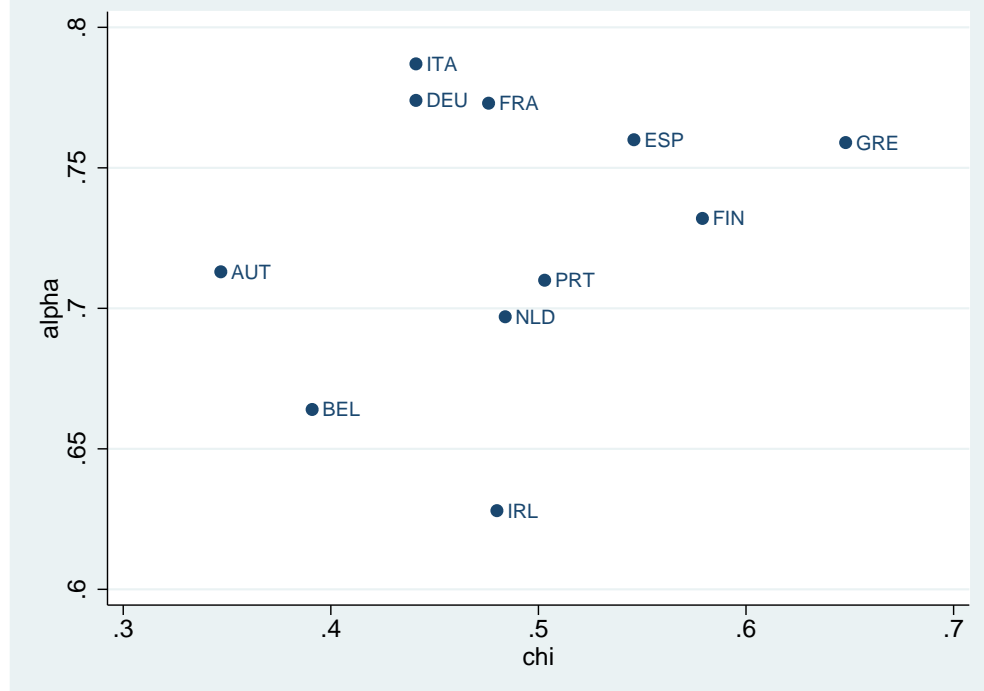

Share of Constrained Households: For the country specific share of credit constrained households, $\chi_{j}$, we use a measure based on the Eurosystem Household Finance and Consumption Survey (HFCS). ${ }^{12}$ For each country, we use the fraction of households with liquid assets below two months of total household gross income to approximate the share of credit constrained households. ${ }^{13}$ The

\footnotetext{
${ }^{12}$ The survey took place in 2010. In Greece and Spain, the data were collected in 2009 and 2008-09 respectively. This survey has been used recently by Kaplan et al. (2014) to quantify the share of hand-to-month households. They define these as consumers who spend all of their available resources in every pay-period, and hence do not carry any wealth across periods. They argue that measuring this behavior using data on net worth (as consistent with heterogeneous-agent macroeconomic models) is misleading because this misses what they call the wealthy hand-tomouth households. These are households who hold sizable amounts of wealth in illiquid assets (such as housing or retirement accounts), but very little or no liquid wealth, and therefore consume all of their disposable income every period. They define hand-to-mouth consumers as those households in the survey whose average balances of liquid wealth are positive but equal to or less than half their earnings.

${ }^{13}$ We thank Caterina Mendicino from the ECB who provided us the data. At the eurozone level, the median household has $18.6 \%$ of its annual income (equivalent to just above two months' income) available in the form of
} 
average for our set of countries is $48 \%$ with a maximum of $64.8 \%$ for Greece and a minimum of $34.7 \%$ for Austria. Ireland did not participate in the survey so for this country we use the average of the eurozone. Note that $b_{j, t}^{h}$ in the model is debt per impatient household so the counterpart to the empirical measure of aggregate debt is $\chi_{j} b_{j, t}^{h}$.

Funding Costs: The cost of fund $\rho_{j, t}$ enters the Euler equation of unconstrained agents. It represents the expected return of savers, the funding cost of firms, etc. The true cost of funds is not directly observable and we base our estimates on several interest rates: (i) loans rates for SMEs; (ii) deposit rates; (iii) wholesale bank funding costs; and (iv) yields on 10-year government bonds. In all cases we compute the difference between the rate in country $j$ and the median of the eurozone in year $t$.

The link between interest rate spreads and funding costs can be complicated. On the one hand, interest rates are not expected returns because they include expected credit losses. On the other hand, we know from a large literature in finance that credit spreads create significant differences in funding costs. This is the basic point of all models with distress costs, agency costs, debt overhang, safety premia, etc. All these models predict that funding costs are increasing in credit spreads, but less than one-for-one. Banks clearly play a special role during the crisis. Many borrowers depend on bank loans and the funding costs of banks are therefore critical for the economy. We use data on banks CDSs to estimate wholesale funding costs. Deposit rates are also informative even though they tend to move more slowly than market rates. They also depend on the credibility of the deposit insurance system. Debt overhang in the banking sector makes it more attractive for banks to invest in the debt of their home sovereign, and this can crowd out private lending. ${ }^{14}$

We want our synthetic measure to be as broad as possible, so ideally we want to use the average of (i) loans rates for SMEs; (ii) deposit rates; (iii) wholesale bank funding costs. Unfortunately we are severely constrained by data availability, as explained in Appendix B.1. The only series that are available for all countries and all years are the spreads on government bonds. We therefore project our three spreads (SME loans, deposits, wholesale funding) on the sovereign spreads and we take the average of the projected values. ${ }^{15}$

$$
\rho_{j, t} \equiv \frac{1}{3}\left(S \hat{M} E_{j, t}+D E \hat{P} O_{j, t}+W \hat{H O L} E_{j, t}\right) .
$$

Figure (27) in Appendix B.3 shows the government bond spreads and our synthetic measure $\rho_{j, t}$. They are of course strongly correlated, but the important point is that $\rho_{j, t}$ is a lot less volatile than the government spread. In the case of Greece for instance, the sovereign spreads exceeds $20 \%$ in

liquid assets (see ECB-HFCS (2013)). Net liquid assets are the sum of deposits, mutual funds, bonds, non self employment business wealth, (publicly traded) shares and managed accounts, net of credit line/overdraft debt, credit card debt and other non mortgage debt

${ }^{14}$ In the limit of a model à la Myers (1977), the bank may end up treating the entire yield as an expected return because it only cares about the non-default state. See Philippon and Schnabl (2013) for a discussion of debt overhang.

${ }^{15}$ We regress each of the country specific interest spreads (loans for SMEs, deposit rates and wholesale bank funding costs captured by CDS rates) on a piecewise linear function of the 10-year government bonds spread. We then take the simple average of the predicted values. 
some years, and this is clearly a reflection of credit risk. Using this raw number in the simulations would make no sense and would lead to too much volatility in spending. As we show below, our synthetic measure seems to perform reasonably well in the simulations.

Finally, agents in our model need to have an estimate of the persistence parameter $\theta$ for the $\rho_{j, t}$ series. A higher persistence amplifies the effect of a given spread shock because it increases its impact on the net present value of future income. It is clearly important to use a longer sample to estimate the persistence so we extend all our spreads series to 2014 and we estimate $\theta$ by running a panel regression with year and country fixed effects. We estimate $\theta$ to be 0.5 , which means that if the spread is $100 \mathrm{bps}$ this year, agents anticipate that it will be 50bps next year.

Scaling: We scale the data in a manner consistent with equation (13). We construct the following benchmark level of nominal GDP for country $j$ at time $t$ :

$$
\hat{Y}_{j, t} \equiv \frac{Y_{j, t_{0}}}{L_{j, t_{0}}} \frac{\bar{L}_{t_{0}}}{\bar{Y}_{t_{0}}} \frac{\bar{Y}_{t}}{\bar{L}_{t}} L_{j, t}
$$

where $t_{0}$ is the base year (2002 in our simulations), $Y_{j, t}$ is GDP, $L_{j, t}$ is population, and $\bar{Y}_{t}$ and $\bar{L}_{t}$ denote the aggregate GDP and population for the eurozone. In words, the benchmark is the nominal GDP the country would have if it had the same per-capita growth rate as the eurozone together with its actual population growth. The key point is that the only country level time-varying variable that we take as exogenous is population growth. We scale all our variables in euros by the benchmark GDP. For GDP itself, we define

$$
y_{j, t} \equiv \frac{Y_{j, t}}{\hat{Y}_{j, t}},
$$

which is one in the base year. For sovereign debt, we define

$$
b_{j, t}^{g} \equiv \frac{B_{j, t}^{g}}{\hat{Y}_{j, t}},
$$

which is equal to the actual debt to GDP ratio in the base year $t_{0}$, but then tracks the level of debt for $t>t_{0}$, as in the model. This is important when we consider deleveraging. With large fiscal multipliers, a reduction in debt might leave the debt to GDP ratio unchanged in the short run. Ratios often give a misleading view of deleveraging efforts. Figure (24) in Appendix B.3 shows the scaled private and sovereign debt series. Figure (25) shows scaled public spending and transfers. Note also that government spending is adjusted for expenditures on bank recapitalization. Prices and wages are the same in our model so we use the average of unit labor costs and consumer prices scaled by the average unit labor cost and consumer prices in the eurozone. For employment, we use employment per capita in deviation to the eurozone average and the base year: $n_{i, t}=\frac{N_{j, t} / L_{j, t}}{N_{j, 2002} / L_{j, 2002}} \frac{N_{j, 2002}^{*} / L_{j, 2002}^{*}}{N_{j, t}^{*} / L_{j, t}^{*}}$. 


\subsection{Reduced Form Simulations}

In our business cycle accounting exercise we take as given the observed series for private debt $\left(b_{j, t}^{h}\right)$, fiscal policy $\left(g_{j, t}, z_{j, t}, \tau_{j}\right)$ and interest rate spreads $\left(\rho_{j, t}\right)$. We define the reduced form model $\Re$ as a mapping

$$
\Re:\left(b_{j, t}^{h}, g_{j, t}, z_{j, t}, \rho_{j, t}\right) \longrightarrow\left(b_{j, t}^{g}, y_{j, t}, n_{j, t}, p_{j, t}, e_{j, t}, . .\right) .
$$

The scaled data on observed shocks that feed the model for each country are shown in figures (24), (25), (26) and (27) in Appendix B.3. For each country, we simulate the path between 2001 and 2012 of nominal GDP $y_{j, t}$, employment $n_{j, t}$, wages $w_{j, t}$, net exports $e_{j, t}$ and public debt $b_{j, t}^{g}$. Figure (4) shows the simulated and observed nominal GDP and net exports series. Figures (18) and (19) in Appendix A.7 show employment and wages.

Figure 4: Reduced Form Model, Nominal GDP and Net Exports

\section{GDP}
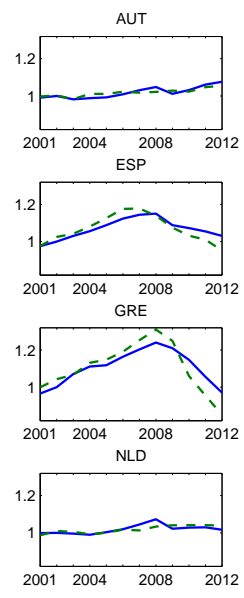
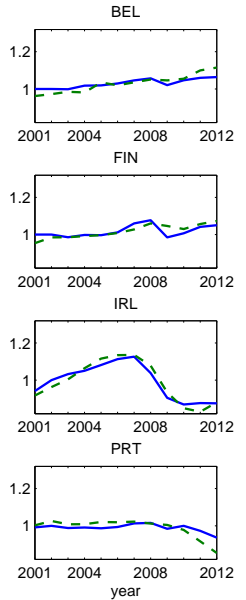
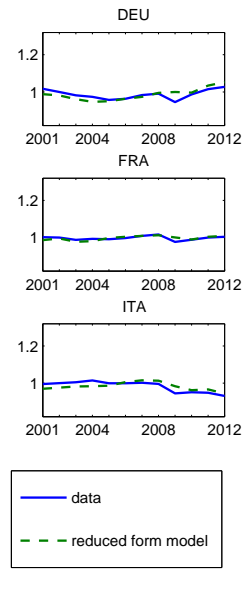

Net Exports
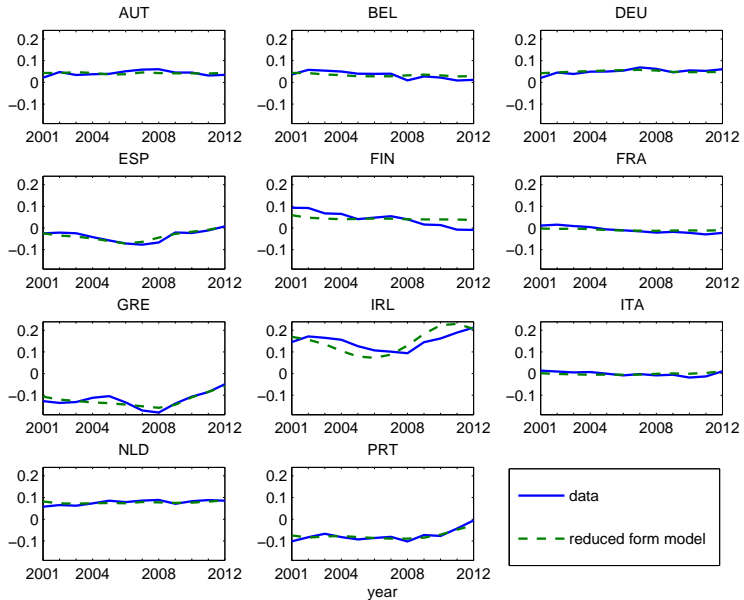

The reduced form model reproduces well the cross sectional dynamics in the eurozone for nominal GDP and net exports. In particular, it replicates well the boom and bust dynamics on nominal GDP and the current account reversal for countries hit by the crisis. It is important to emphasize that there is essentially no degree of freedom in our simulations. No parameter is set to match the aggregate data. The model is entirely constrained by observable micro estimates and by equilibrium conditions. The only parameter that we can adjust is the slope of the Phillips curve $\kappa$ but it does not affect the nominal GDP in euro, it only pins down the allocation of nominal GDP between prices and quantities (employment).

It is nonetheless important to focus on the errors made by the model. There are three main simulations errors. One is that the model over-predicts the boom/bust cycle in Greece. We think that one reason might be that the increase in government spending took the form of higher wages 
to public servants. To the extent that these agents are not credit constrained, our model can overestimate the departures from Ricardian equivalence. The second issue is the timing of Irish net exports. The data seem to lag the model by one year. We are not quite sure why this is the case, and this issue will appear again in our structural simulations. The third issue is in fact a good sign: in Germany, the model fails to account the increase in the natural rate of employment following the Hartz reforms of 2003-2005. We think this should show up as a change in the Phillips curve, and it does.

\section{Structural Model}

Private leverage, spreads and fiscal policy are interrelated and our goal in this section is to identify the structural relations between the three variables. We think of country dynamics as being driven by three structural shocks. The first one is a boom/bust cycle in private debt, which we call credit cycle for short. The second one is a political economy bias in government spending that creates fiscal imbalances. The third is a sudden stop that threatens the stability of the eurozone. Formally, we think of the structural model $\Im$ as a mapping

$$
\Im:(\text { Credit Cycle, Political Economy, Sudden Stop }) \longrightarrow\left(b_{j, t}^{h}, g_{j, t}, \rho_{j, t}, y_{j, t}, \ldots\right)
$$

The key point of the structural model is to explain the variables that we took as exogenous in the reduced form model (15). Our identification strategy is based on a mix of theoretical modeling and empirical identification using instrumental variables. We do not claim to provide micro-foundations for every detail of the model. Given the range of data and economic forces that we need to capture, this is not feasible. But we mean that, either there is an explicit theoretical equation, or there is an empirical equation that allows us to identify the influence of one variable on the others.

\subsection{Using the U.S. to Identify Private Debt Dynamics}

A serious identification challenge is to figure out how private deleveraging would play out if without sudden stops. It is clear that there would be some deleveraging in any case, but exactly how fast and how much, we do not know. It is also rather intuitive that places that experience the largest increase in debt during the boom experience the largest decrease during the bust. This makes it particularly difficult to come up with plausible instruments. Our identification strategy is then to use the United States as a control group to estimate deleveraging without sudden stops. We estimate the following model for deleveraging in a panel of U.S. states

$$
b_{j, t}^{h, U S}=\hat{\alpha}_{1} b_{j, t-1}^{h, U S}+\sum_{k=2002,2005,2008} \hat{\alpha}_{k} b_{j, k}^{h, U S}+\epsilon_{j, t}
$$


for $t=2009, . ., 2012, j=1, . .52$, and $b_{j, t}^{h}$ is household debt in state $j$ at time $t$, rescaled exactly as explained above for the eurozone. ${ }^{16}$ The idea is that these private leverage cycles reflect various global and financial factors: low real rates, financial innovations, regulatory arbitrage of the Basel rules by banks, real estate bubbles, bank governance, etc. ${ }^{17}$ To a large extent these forces were present both in Europe and in the US. The difference of course is that there was no sudden stops within the US. Hence, we interpret the US experience as representative of a deleveraging outcome in a monetary union without sudden stops. ${ }^{18}$ The estimated coefficients $\alpha_{k}^{U S}$ are negative, capturing the fact that states that accumulate more private debt during the boom deleverage more during the bust. We then take the estimated coefficients $\hat{\alpha}_{k}$ and use them to construct predicted deleveraging in eurozone countries:

$$
\hat{b}_{j, t}^{h}=\hat{\alpha}_{1} b_{j, t-1}^{h,}+\sum_{k=2002,2005,2008} \hat{\alpha}_{k} b_{j, k}^{h,}
$$

for $t=2009, . ., 2012$ and $j=1 . .11$. Figure (5) illustrates the results for California and Ireland.

Figure (5) suggests the Irish private sector paid back its debts faster than one would expect if Ireland had be a U.S. state. This is also the case for other countries that experienced a sudden stop. We can now present our structural equation for eurozone countries for $t=2009, . ., 2012$ :

$$
b_{j, t}^{h}=\hat{b}_{j, t}^{h}+\lambda^{\rho, h} \rho_{j, t} .
$$

Private leverage is equal to the prediction from the U.S. experience plus the impact of the increase in funding cost. The first element $\hat{b}_{j, t}^{h}$ is interpreted as an exogenous shock. The second element, the impact of the spread, is endogenous and captures various transmission channels, such as a decrease in bank lending.

Figure 5: Private Deleveraging
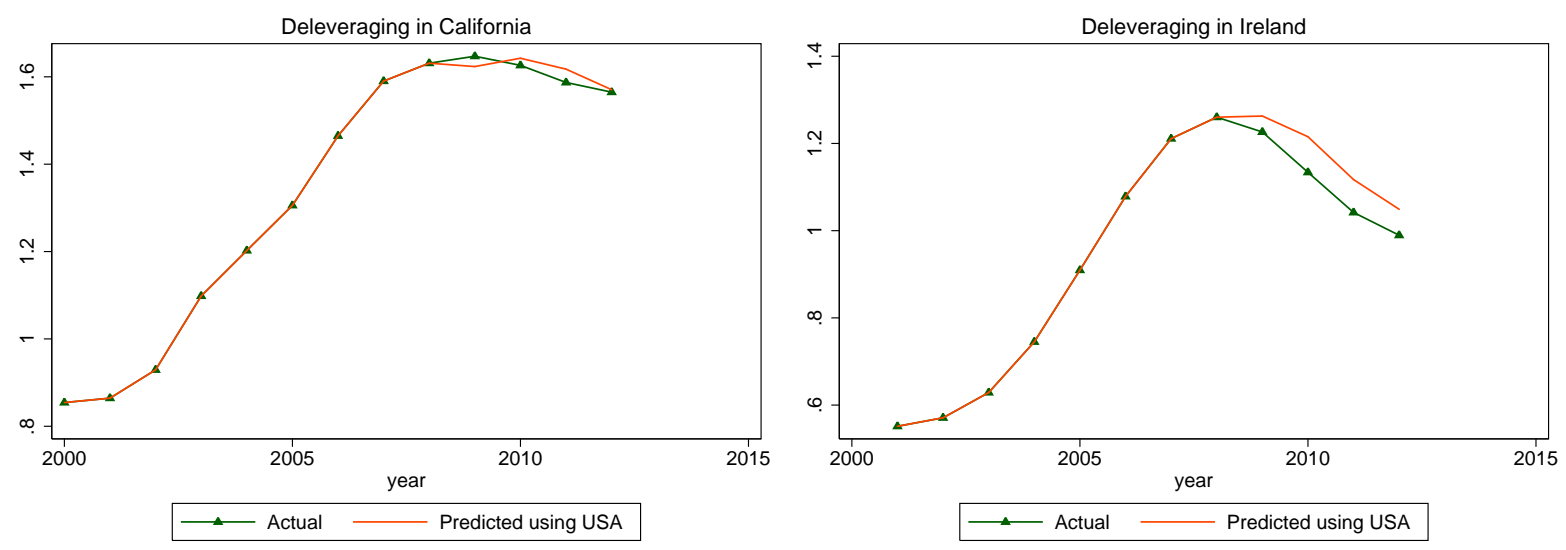

\footnotetext{
${ }^{16}$ One issue we have to deal with is that mortgage defaults are much more prevalent in the U.S., because of differences in mortgage regulations. Deleveraging in the model does not happen via default, so we must add to the series of household debt in US states the amount of debt which has been defaulted upon.

${ }^{17}$ See Cunat and Garicano (2009) on the case of Spain.

${ }^{18}$ We discuss differences in local fiscal policy in Appendix B.2.
} 


\subsection{Funding Costs and Sudden Stops}

We assume that the cost of fund for country $j$ at time $t$ is

$$
\rho_{j, t}=\sigma_{t} \times\left[\lambda_{0}^{\rho}+\lambda^{g, \rho} b_{j, t}^{g}+\lambda^{g, h i g h, \rho} b_{j, t}^{g, h i g h}+\lambda^{h, \rho} b_{j, t}^{h}+\lambda^{r e c, \rho} \operatorname{recap}_{j, t}\right]
$$

where $\sigma_{t}$ captures the time varying risk of a sudden stop. This equation says that funding costs start to diverge when there is a sudden stop in the eurozone and that the extent to which this happens in different countries depends on public debt $b_{j, t}^{g}$, private debt $b_{j, t}^{h}$ but also recapitalization of the financial sector $\left(\right.$ recap $\left._{j, t}\right) .{ }^{19}$ This is a fairly standard equation that emphasizes the interaction between a common risk factor $\left(\sigma_{t}\right)$ and local sensitivities (debt levels). The time varying risk is needed to explain rapid changes in spreads while debt levels tend to be very persistent. The local sensitivities are needed because not all countries are hit by sudden stops. Our specification captures financial frictions associated with high leverage (debt overhang, risk shifting, adverse selection, runs, etc.). We allow the impact of public debt on spreads to be non linear to take into account the case of Greece. More specifically, we allow the coefficient to be higher for levels of debt above 90\% of GDP so we define $b_{j, t}^{g, h i g h} \equiv\left(b_{j, t}^{g}-0.9\right)\left(b_{j, t}^{g}>0.9\right)$. In our data, this non linear effect is only significant for Greece.

We estimate the coefficients $\lambda$ 's on the period 2008-2012 for the 11 eurozone countries. We do so by running instrumental variable regressions. ${ }^{20}$ For $\rho_{j, t}$ in equation (17) we use as instruments the government debt in 2002, 2007 and 2008 as well as total public expenditures in 2002 and 2008. For government and private debt $b_{j, t}^{g}$ and $b_{j, t}^{h}$ and recapitalization $\left(\right.$ recap $\left._{j, t}\right)$, in equation (18), we use as instruments government debt levels $\left(b_{j, t}^{g}\right)$ lagged three years, the exogenous component of private debt (and its lag) predicted by the US experience $\hat{b}_{j, t}^{h}$. To capture the possibility and the size of a sudden stop in the eurozone, we measure the coefficient $\sigma_{t}$ as the mean of the observed absolute value of spreads in the eurozone. As expected, it is close to zero up to 2007 and starts increasing in 2008 with a maximum in 2012. The estimated coefficients, which we will use in our simulations, are shown in Table (2).

Table 2: Coefficients Estimated with Instrumental Variables.

\begin{tabular}{ccccc}
$\lambda^{\rho, h}$ & $\lambda_{0}^{\rho}$ & $\lambda^{g, \rho}$ & $\lambda^{h, \rho}$ & $\lambda^{r e c, \rho}$ \\
\hline-1.8 & -2.3 & 2 & 1.2 & 15 \\
$(0.179)$ & $(0.16)$ & $(0.4)$ & $(0.3)$ & $(3)$ \\
Note: & standard errors in parenthesis.
\end{tabular}

Note: standard errors in parenthesis.

\footnotetext{
${ }^{19}$ Favero (2013) also finds that fiscal fundamentals matter for eurozone spreads in interaction with the time varying perceived risk of a eurozone breakup.

${ }^{20}$ For the non linear effect of public debt on spreads, we set $\lambda^{g, h i g h}=1.3$ since it gives the best fit for Greece.
} 


\subsection{Fiscal Policy}

Our last task is to specify a fiscal policy function for the different governments. We assume that the government seeks to stabilize employment but is constrained by its cost of funds. The government cuts spending when $\rho_{j, t}$ is positive. ${ }^{21}$ We allow the funding constraint to have a stronger impact for higher levels of the rescaled spreads (above 100 basis points): $\rho_{j, t}^{\text {high }} \equiv \max \left(\rho_{j, t}-0.01,0\right)$. This non linear effect is important for Greece and to a lesser extent for Portugal. Hence, the policy rule for government spending, with parameters $\gamma^{n}, \gamma^{\rho}$ and $\gamma^{\rho, h i g h}$, is given by:

$$
\begin{aligned}
& g_{j, t}=\tilde{g}_{j, t}+\gamma^{n}\left(n_{j, t}-\bar{n}\right)+\gamma^{\rho} \rho_{j, t}+\gamma^{\rho, h i g h} \rho_{j, t}^{h i g h}, \\
& z_{j, t}=\tilde{z}_{j, t}+\gamma^{n}\left(n_{j, t}-\bar{n}\right)+\gamma^{\rho} \rho_{j, t}+\gamma^{\rho, h i g h} \rho_{j, t}^{h i g h},
\end{aligned}
$$

where $\tilde{g}_{j, t}$ and $\tilde{z}_{j, t}$ are country specific drifts,

$$
\begin{aligned}
& \tilde{g}_{j, t}=g_{j, 0}+\delta_{j}^{g}\left(\min \left(t, t_{1}\right)-t_{0}\right)-\delta_{j}^{g} \max \left(t-t_{1}, 0\right), \\
& \tilde{z}_{j, t}=z_{j, 0}+\delta_{j}^{z}\left(\min \left(t, t_{1}\right)-t_{0}\right)-\delta_{j}^{z} \max \left(t-t_{1}, 0\right),
\end{aligned}
$$

with $t_{0}=2002$ and $t_{1}=2008$. Hence, $\delta_{j}^{g}$ represents the average "excess" annual spending growth rate during the boom years. We interpret this drift as a political bias in spending decisions that is reversed after 2008. ${ }^{22}$ What matters for us is that countries display different degrees of spending bias during the boom years, and we want to analyze to what extent this spending drift during the boom years contributes to the crisis.

Table 3: Fiscal policy coefficients

$$
\begin{array}{ccc}
\gamma^{n} & \gamma^{\rho} & \gamma^{\rho, h i g h} \\
\hline-0.8 & -2.5 & -1.0
\end{array}
$$

Table 4: Biases in government spending

\begin{tabular}{|c|c|c|c|c|c|c|c|}
\hline \multicolumn{4}{|c|}{$\delta_{j}^{g}$} & \multicolumn{4}{|c|}{$\delta_{j}^{z}$} \\
\hline \hline Spain & Greece & Ireland & Portugal & Spain & Greece & Ireland & Portugal \\
\hline $1.5 \%$ & $0 \%$ & $0.5 \%$ & $0 \%$ & $1.0 \%$ & $3.5 \%$ & $2.0 \%$ & $0 \%$ \\
\hline
\end{tabular}

\footnotetext{
${ }^{21}$ In fact we use the lagged spread simply because it fits better, which probably reflects implementation lags in fiscal policy. This is not related to the identification of the model and our results are not sensitive to this detail.

${ }^{22}$ The fact that it is reversed is not very important for our results. We could assume that $\tilde{g}_{j, t}$ stays constant after $t_{1}$ and our simulations would be similar. In fact, our counter-factual results would be stronger since the model would then choose a larger $\gamma^{\rho}$ to fit the data. But this can create issues of debt sustainability if we simulate the model beyond 2012 and we assume that the spreads normalize. In practice we also see that governments are trying to reverse some of the spending decisions they made during the boom years. The change in political bias might come from new fiscal rules agreed at the EU level, from explicit requirements for countries in a program, or more broadly from a shift in attitudes and beliefs about fiscal responsibility
} 
We focus on the four countries that are most harshly hit by the crisis, namely Spain, Greece, Ireland and Portugal. We choose our parameters in the policy rule $\gamma^{n}$ and $\gamma^{\rho}$ and the spending and transfer drift coefficients $\delta_{j}^{g}$ and $\delta_{j}^{z}$ such that the model reproduces dynamics of public debt (equivalently, spending and net taxes) during the boom. This leads us to the parameters given in Tables (3) and (4). The spending biases necessary to reproduce the debt dynamics is larger in Greece than in the other periphery countries. It is intermediate in Ireland and Spain and null in Portugal. In Greece, the fiscal drift is entirely in the form of transfers reflecting the high growth rate of wages in the public sector and the impact of the pension system in the boom years (see Fernández Villaverde et al. (2013)). Finally, we need to take into account the Greek debt restructuring. Greece benefits from low interest rates, extended repayment periods for the EU and IMF rescue package, and a large reduction of outstanding debt. Altogether, we estimate that this is equivalent to a decrease of 50 points of GDP, mostly in 2012.

Table 5: : Goodness of fit, structural model

\begin{tabular}{|c|c|c|c|c|}
\hline & ESP & GRE & IRL & PRT \\
\hline \hline$y_{j, t}$ & 0.87 & 0.61 & 0.78 & 0.39 \\
\hline$n_{j, t}$ & 0.95 & 0.62 & 0.92 & 0.50 \\
\hline$p_{j, t}$ & 0.95 & 0.23 & 0.73 & 0.74 \\
\hline$b_{j, t}^{g}$ & 0.93 & 0.95 & 0.94 & 0.92 \\
\hline$\rho_{j, t}$ & 0.90 & 0.87 & 0.98 & 0.82 \\
\hline$e_{j, t}$ & 0.80 & 0.70 & 0.2 & 0.75 \\
\hline
\end{tabular}

Note: Goodness of fit is the share of variance explained by the model. It is measured as $1-r s s_{j} / t s s_{j}$ where $t s s_{j}$ is the total sum of squares and $r s s_{j}$ is the residual sum of squares. For instance, for GDP, we have $t s s_{j} \equiv \sum_{t=2001}^{2012}\left(y_{j, t}-\bar{y}_{j}\right)^{2}$, where $y_{j, t}$ and $\bar{y}_{j}$ are the actual GDP and its sample mean, and $r s s_{j} \equiv$ $\sum_{t=2001}^{2012}\left[y_{j, t}-\hat{y}_{j, t}+\overline{\hat{y}}_{j}-\bar{y}_{j}\right]^{2}$, where $\hat{y}_{j, t}$ is the prediction of the model and $\overline{\hat{y}}_{j}$ its sample mean.

\subsection{Fit of the structural model}

The structural model is a constrained version of the reduced form model presented earlier. We can now formally write equation (16) as

$$
\Im:\left(\hat{b}_{j, t}^{h} ; \delta_{j}^{g}, \delta_{j}^{z} ; \sigma_{t}\right) \longrightarrow\left(b_{j, t}^{h}, g_{j, t}, z_{j, t}, \rho_{j, t} ; b_{j, t}^{g}, y_{j, t}, n_{j, t}, p_{j, t}, e_{j, t}, . .\right)
$$

subject to the equilibrium condition of the model and the structural equations (17), (18) and (19). There are three sets of exogenous factors: the fiscal biases $\delta_{j}^{g}$ and $\delta_{j}^{z}$, the predicted private credit cycle $\hat{b}_{j, t}^{h}$, and the sudden stop shock $\sigma_{t}$. 
Figure 6: Structural Model, Nominal GDP and Employment

GDP
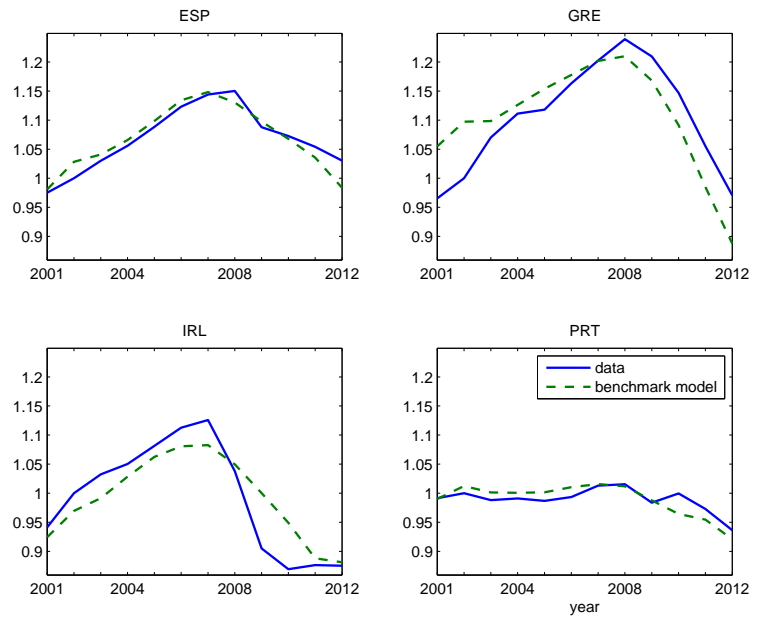

Employment
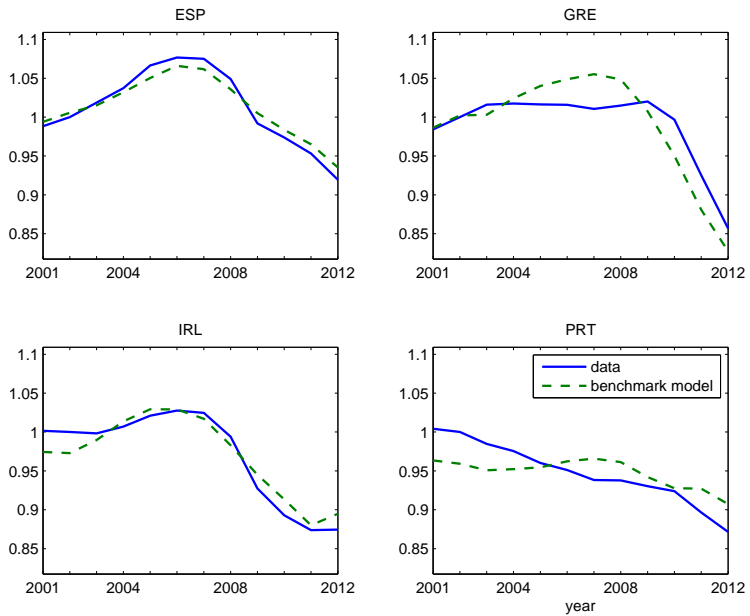

Figure 7: Structural Model, Government Debt and Funding Costs

Government Debt
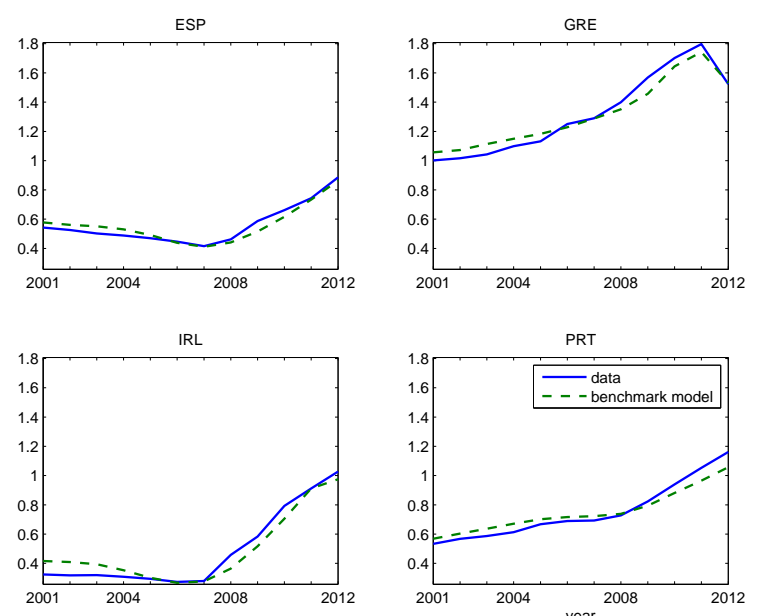

Funding Costs
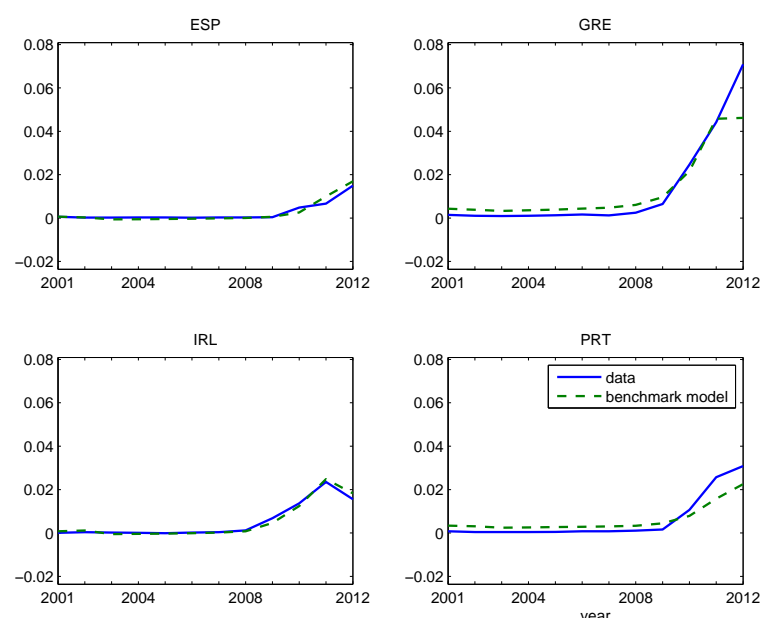

Figure (6) compares the actual and predicted series for nominal GDP and employment in the four periphery countries. ${ }^{23}$ Figure (7) does the same for public debt and funding costs. The model accounts well for the timing and amplitude of the boom and bust episodes. Table (5) reports the

\footnotetext{
${ }^{23}$ As with the reduced form figures, we add the difference between the mean of the data and the mean of the structural model. The observed and predicted net exports are shown in figure (20) in Appendix A.7
} 
goodness of fit of the structural model, defined as the share of the variance explained by the model. The goodness of fit is a number between $-\infty$ and 1 . It is positive if the model helps reduce the unexplained variance, and it is one if the model fits perfectly. The fit is good, but there are some issues. The model over-predicts employment and nominal GDP in Greece during the boom (see the discussion above for the reduced form case). There is some timing issues with Ireland. In Portugal, funding costs are a bit low and the model misses the downward employment trend early in the sample. But, overall, the goodness of fit makes us confident that we can use the model to perform our counter-factual experiments. ${ }^{24}$

\section{Counterfactual experiments}

The goal of this section is to provide counterfactual simulations of what would happen to Greece, Spain, Ireland and Portugal if they followed a different set of policies. We consider four counterfactuals:

- fiscal policy: what happens with more conservative fiscal policies before 2008 ?

- macro-prudential policies: what happens with limits on private debt before 2008?

- monetary policy: what happens if ECB prevents the sudden stop in 2008?

- fiscal devaluation: what happens if these countries devalue in 2009 ?

For the counterfactual experiments, we use the structural equations (17), (18) and (19) with the estimated coefficients discussed above. In all our experiments, we report on the same graph the actual data and the predicted counter-factual series. ${ }^{25}$ The simulations generate series for public debt, private debt, employment, nominal GDP, net exports and spreads on the period 2001-2012, using debt in 2000 as an initial point.

\subsection{Counterfactual with a more conservative fiscal policy in the boom}

How would countries have fared if they had followed more conservative fiscal policies during the boom? We answer this question by setting $\delta_{j}^{g}$ and $\delta_{j}^{z}$ equal to zero for the four periphery countries. For Spain, Ireland and Portugal all the other benchmark parameters are left unchanged. For Greece, we need to deal with the debt relief issue. Given that the counterfactual conservative fiscal policy generates debt to GDP ratios much lower than in the data in 2011 and 2012, we assume that debt relief would not have taken place. Hence, for Greece the counterfactual is the combination of a more

\footnotetext{
${ }^{24}$ It might be worth emphasizing that the fit is absolutely not mechanical. Recall that our model has no productivity shock, which means that we do not extract any information from the actual GDP series. Another important fact, that we do not have the space to discuss here, is that all these results change dramatically if we use the wrong series. The goodness of fit turns negative if we do not use Trade in Value-Added to estimate foreign demand shocks, or (even worse) if we use the raw government spread as an estimate of $\rho$.

${ }^{25}$ The predicted series is defined as data + (structural model with counterfactual parameters - structural model with benchmark parameters).
} 
conservative fiscal policy but also the elimination of a transfer of around $50 \%$ of nominal GDP in 2011-2012.

Figure 8: Government Debt and Funding Costs with Conservative Fiscal Policy Government Debt

Funding Costs
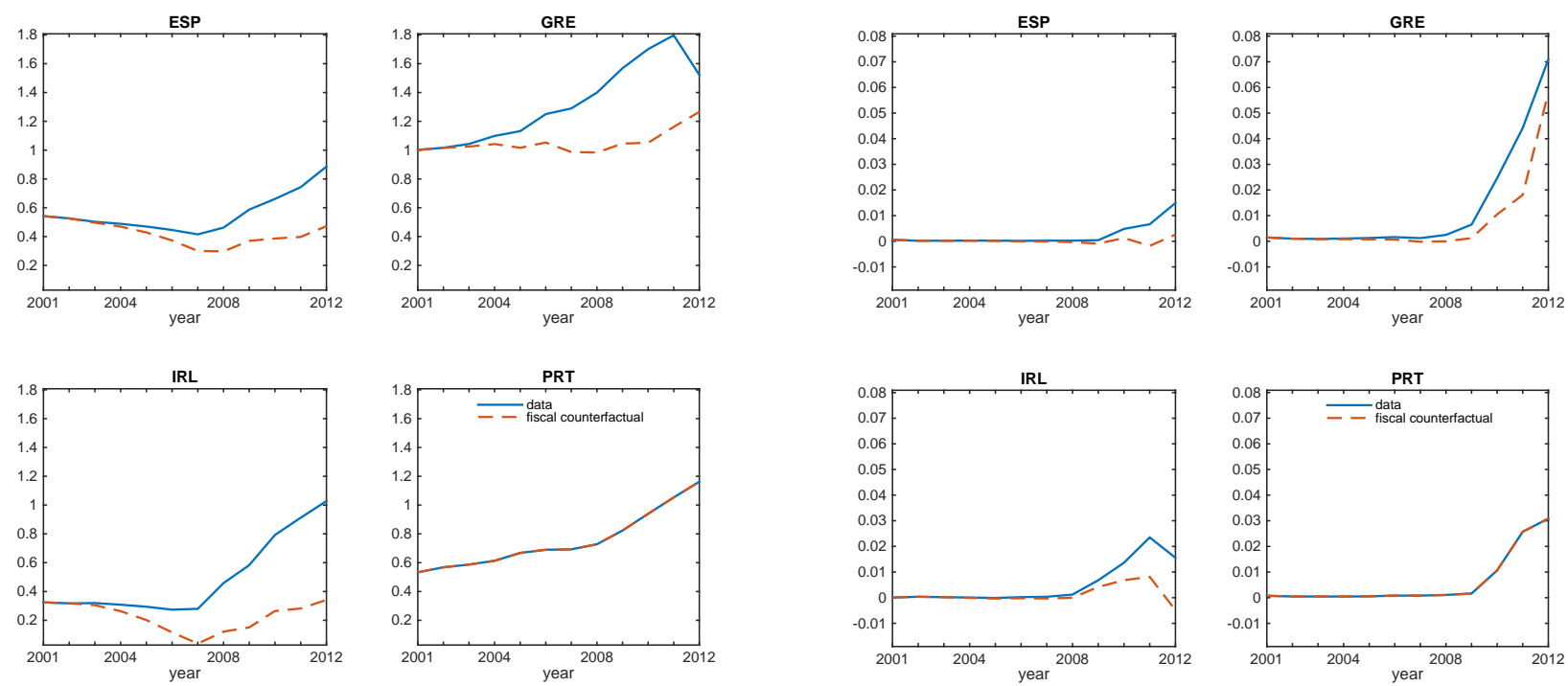

Figure (8) shows that the elimination of the spending bias dramatically changes the public debt accumulation in Greece (remember that this more conservative fiscal policy in Greece also means that it does not benefit from the debt relief at the end of the period). It also has a significant impact in Ireland and Spain, but not in Portugal where we estimated no bias. This large change in the public debt in turns reduces funding costs during the sudden stop in Ireland and Spain but less so in Greece as shown on the right panel of figure (8) because Greece still has a high level of debt when hit by the sudden stop. Lower funding costs reduce fiscal austerity during the bust. 
Figure 9: Employment with Conservative Fiscal Policy
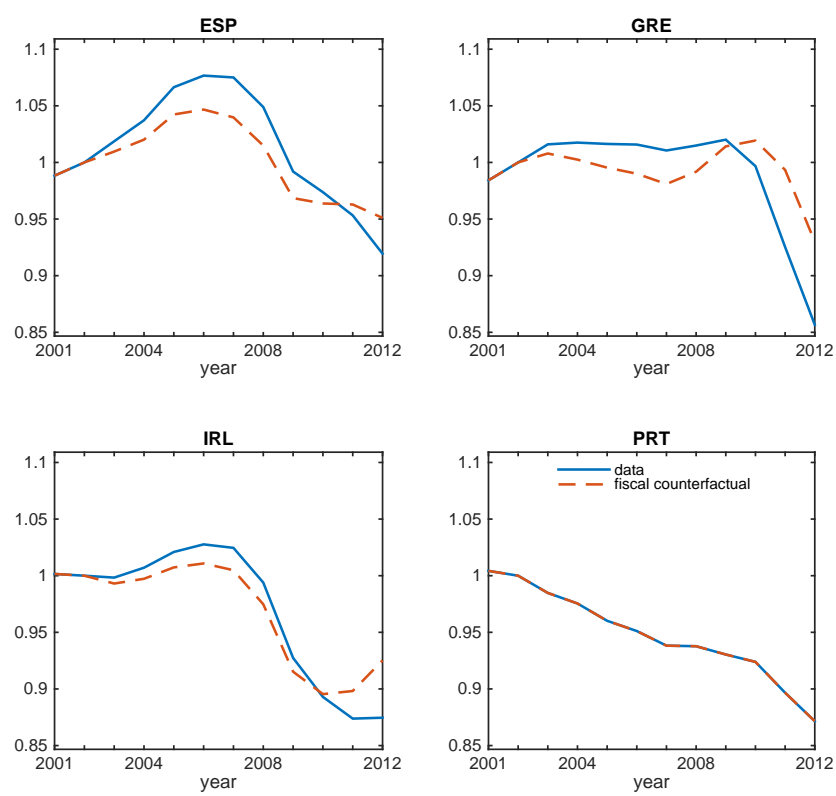

Figure (9) shows that a conservative fiscal policy allows Greece to stabilizes employment. The actual employment loss of 15.8 percentage points (relative to the eurozone average) between 2008 and 2012 would have been almost halved with this more conservative fiscal policy. The counterfactual conservative fiscal policies in Spain and Ireland do not eliminate the boom-bust cycle but allow for an earlier exit from the recession, especially in Ireland. We have also checked that a counterfactual with a pro-active fiscal adjustment reducing Portuguese public debt during the period 2001-2008 would have allowed Portugal to have a somewhat milder recession.

Finally, note that, in the counterfactual experiment, Ireland eliminates all public debt by the end of the boom, and Spain reduces its public debt to around 30\% of GDP. This does not seem very realistic, and it suggests that fiscal policy is unlikely to be enough to stabilize an economy subject to a large buildup of private debt. We therefore now turn to macro-prudential policies.

\subsection{Counterfactual with macro-prudential policies in the boom}

In this counterfactual we imagine that countries are able to prevent the private leverage boom. We assume that $\hat{b}_{j, t}^{h}$ remains constant. We take into account the impact of such policy on the recapitalization of financial institutions during the bust: using a cross-sectional regression, we estimate that a reduction of private debt by one euro during the boom reduces recapitalization needs by 0.25 euro during the bust. The macro-prudential policy in the boom therefore reduces public debt and spreads. Figure (10) shows that this macro-prudential policy partially stabilizes employment in all four countries. This is especially true in Ireland: whereas in the data employment falls from 2008 to 2012 by almost $12 \%$ more than the Eurozone average, in the counterfactual it falls by only 
4.2\% more than the Eurozone average. Not surprisingly given that there was little private leverage boom in Portugal, the impact of a counterfactual macro-prudential policy is small in this country. The comparison of the conservative fiscal counterfactual and of the macro-prudential counterfactual shows that the private leverage boom was the key igniting element of the crisis in Ireland and Spain and that fiscal policies during the boom played a secondary role. The opposite is true for Greece. Given that the fiscal drifts are not affected in this counterfactual, the fiscal rule (that contains both a spending and transfer drift and a countercyclical component) induces a larger buildup of public debt than in a situation without macro-prudential policy.

Figure 10: Employment with Macro-Prudential Policies
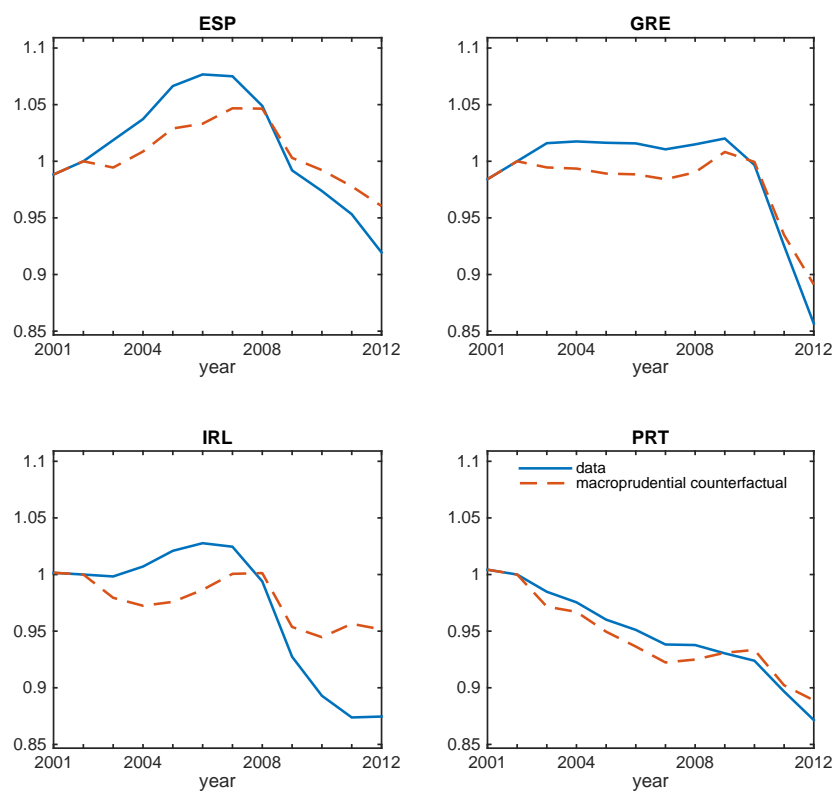
Figure 11: Government Debt and Funding Costs with Macro-Prudential Policies Government Debt
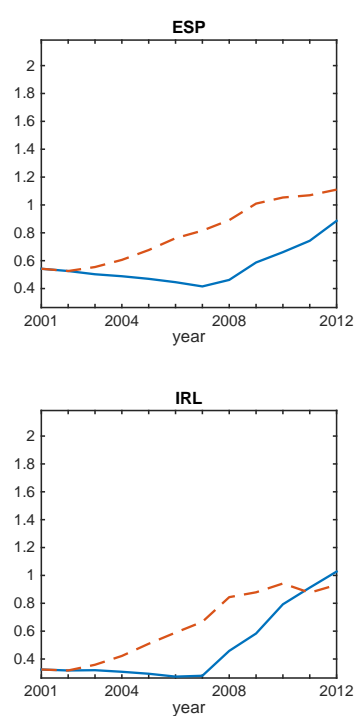
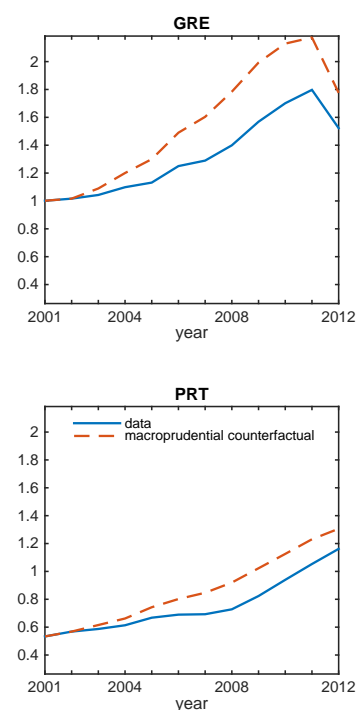

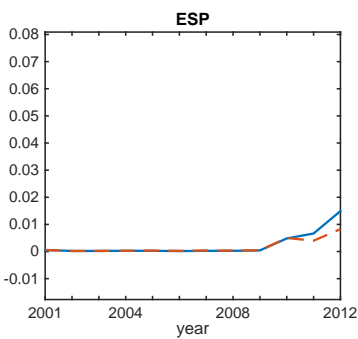

Funding Costs
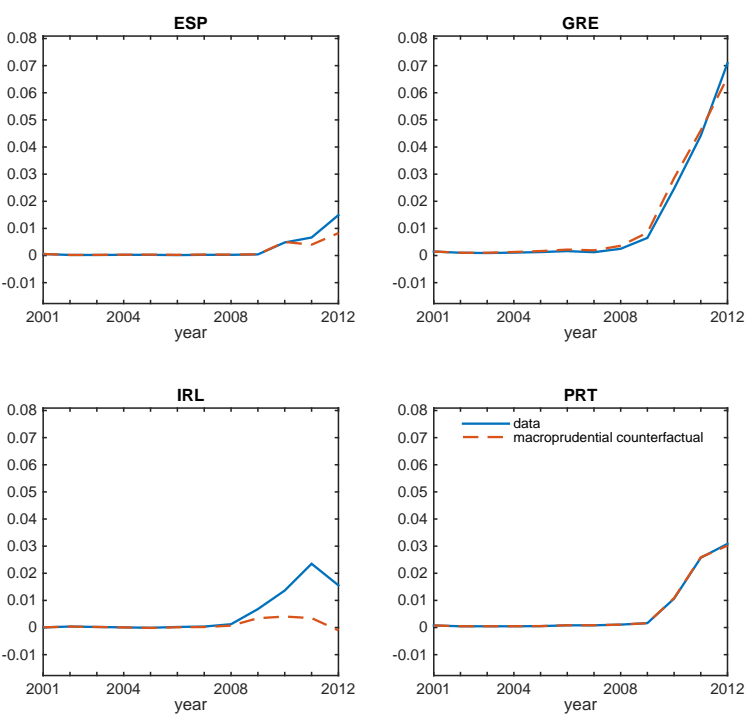

The public debt buildup in the boom can be seen in figure (11) in Spain, Greece and Ireland: larger public debt is substituted to private debt to achieve the employment target. There are two opposite effects on spreads: on the one hand the reduction in private leverage and in bank recapitalization reduces spreads. On the other hand, the larger buildup of public debt pushes spreads upward. In Ireland, the first effect clearly dominates as spreads disappear in this counterfactual (see figure 11) largely because this counterfactual eliminates the need for bank recapitalization. In the other three countries, this is not the case. This counterfactual suggests that macro-prudential policies that do not come with a more prudent fiscal rule may not have been sufficient to generate a fiscally sustainable stabilization of employment. In this sense, macro-prudential policies to constrain private leverage and prudent fiscal policies to constrain public debt are complements not substitutes. Indeed, we checked that in the case of Ireland and Spain, only a counterfactual that combines prudent fiscal policies and macro-prudential policies succeeds in stabilizing both total debt and employment.

\subsection{Counterfactual with "whatever it takes" in 2008}

In this counterfactual we ask the following question: what would have happened if the announcements of July 2012 (Mario Draghi's declaration "Whatever it takes") and September 2012 (the OMT program) had come earlier. These announcements were successful in reducing the risk of a euro breakup, financial fragmentation and the sudden stop. The experiment is to imagine that these actions were implemented and successful in 2008 rather than 2012. Specifically, we assume that $\sigma_{t}$, 
the mean of the absolute value of spreads in the eurozone, in equation (18), is kept at its low 2007 level from 2008 on. This effectively eliminates (in Spain and Ireland) or strongly reduces (in Greece and Portugal) the dramatic rise in funding costs as illustrated in figure (12).

Figure 12: Funding Costs with Early ECB Intervention
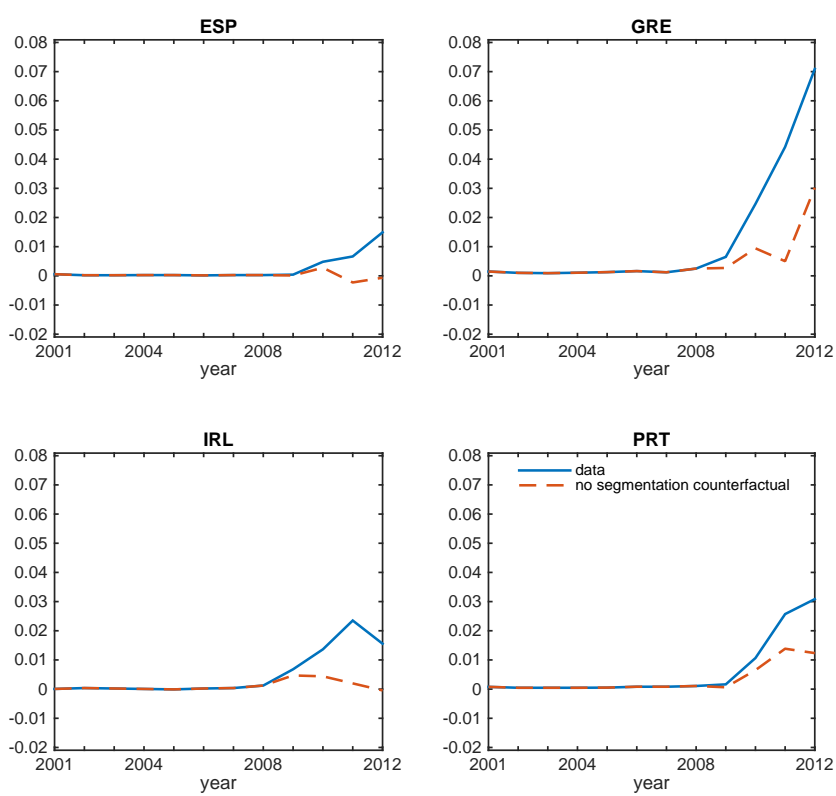

Figure 13: Employment and Government Debt with Early ECB Intervention Employment

Government Debt
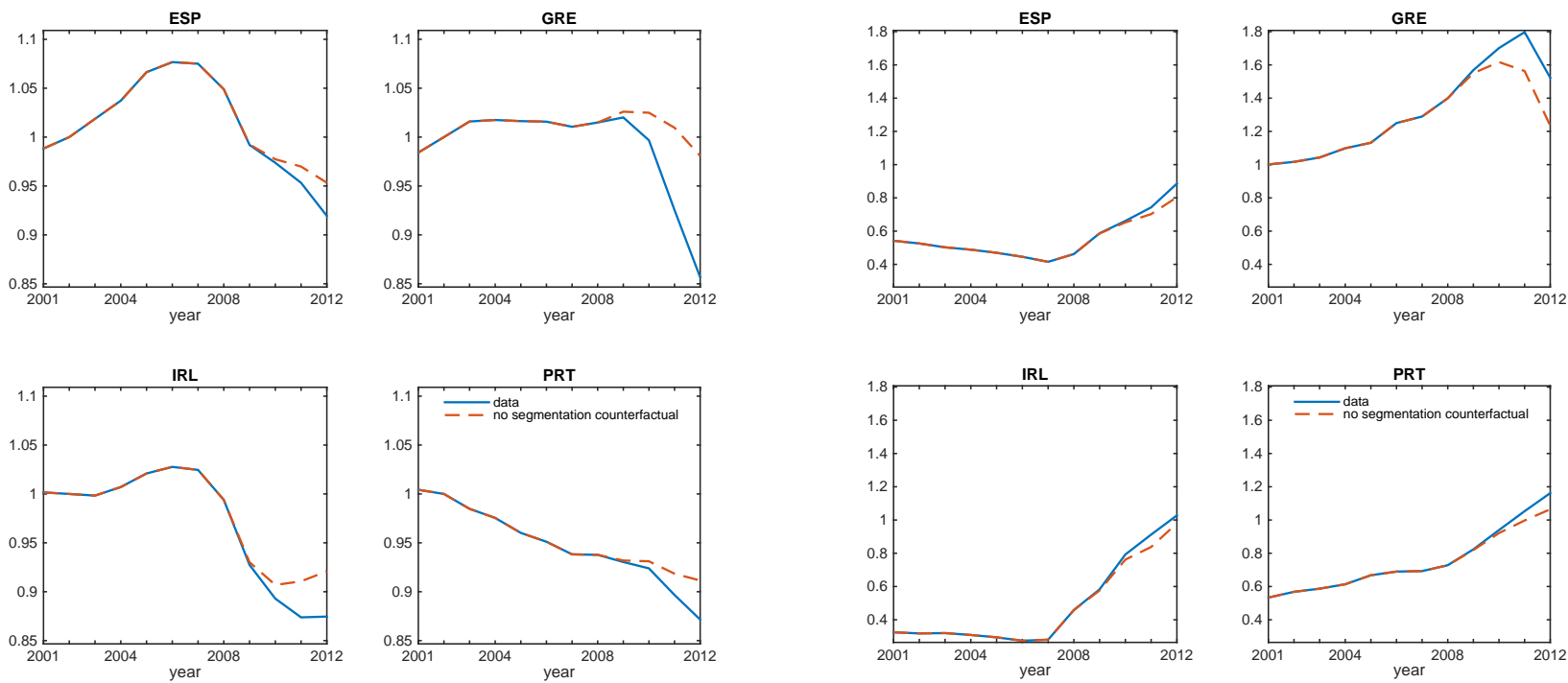
The lower funding costs enable countries to stabilize employment (see figure 13). Interestingly, the employment dynamics of Ireland then look similar to the ones of many U.S. states. There is a large private leverage boom/bust cycle, but it is followed by a recovery starting in 2011. Finally, although not stabilized, public debt is a bit lower than in the data as illustrated in figure (13). This is due to larger fiscal receipts thanks to better GDP growth. Lower funding costs affect aggregate spending and employment through three channels: 1) savers do not slash spending as much (see the Euler equation 14); 2) the leverage of borrowers does not fall as much (see equation 17) which in turn positively affects their spending; 3) fiscal austerity is reduced because fiscal policy (19) is less constrained by the funding costs. We have checked that in all countries the fiscal channel is by far the most important channel through which lower funding costs help stabilize employment.

\subsection{Counterfactual with fiscal devaluation}

In this counterfactual we ask the following question: what would have happened if periphery countries had been able to engineer a fiscal devaluation during the bust in order to recoup part of the competitiveness they had lost during the boom years? This is close to a "flexible" exchange rate counterfactual, but it is not identical because a fiscal devaluation does not impact the net foreign asset position. ${ }^{26}$

Figure 14: Employment and Government Debt with Fiscal Devaluation

Employment

Government Debt
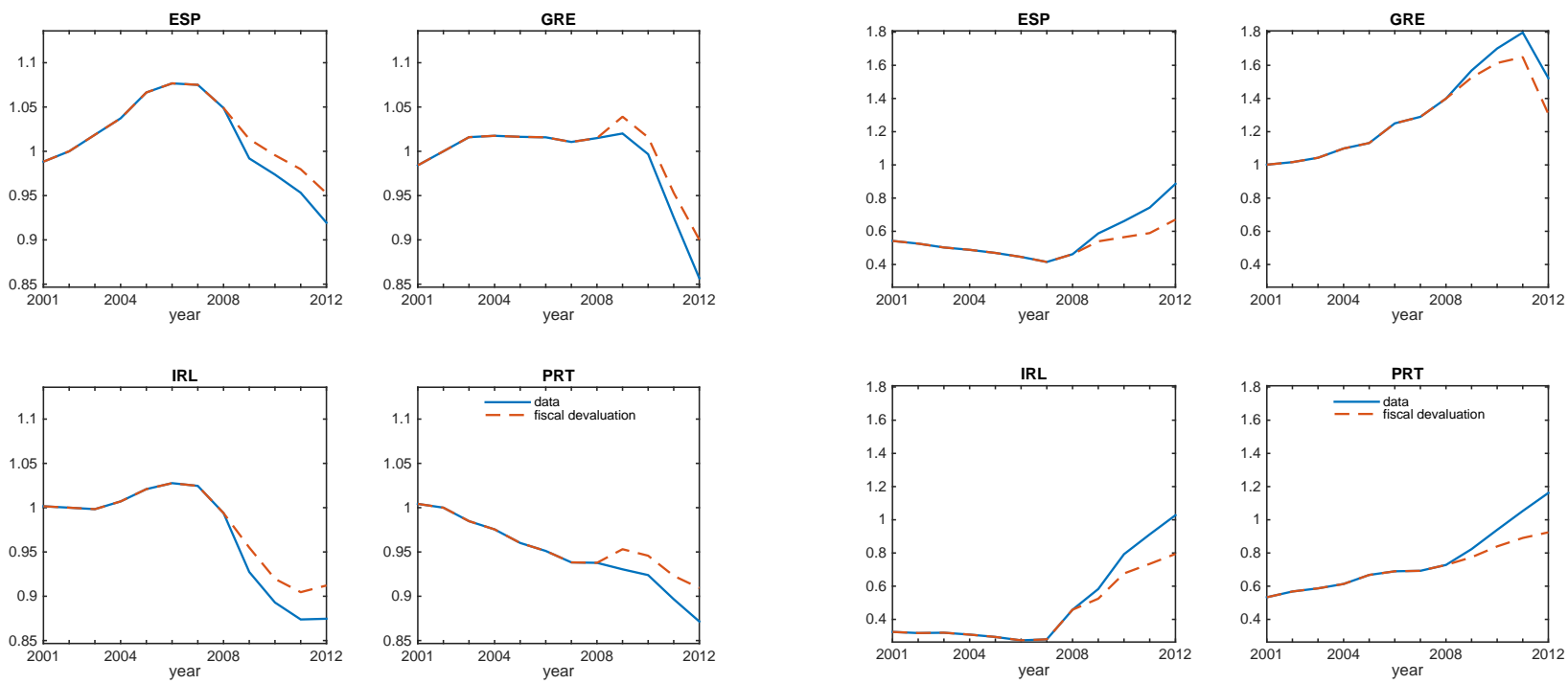

\footnotetext{
${ }^{26}$ See Franco (2013) and Farhi et al. (2014) for conditions under which a fiscal devaluation is equivalent to an exchange rate adjustment.
} 
More precisely, we assume that the fiscal devaluation is achieved through the combination of a VAT tax on all domestic expenditures (private and public) and a payroll subsidy on wages. Appendix A.8 details how the equilibrium conditions are amended. The VAT is paid by firms and rebated to exporters. The payroll subsidy on labor is paid to domestic firms. To simplify further we assume that the VAT rate and the payroll subsidy are equal to $\tau_{v, j, t}$. Hence, export prices $p_{j, t}^{*}$ fall so foreign demand increases to $\frac{f_{j, t}}{\left(1-\tau_{v, j, t}\right) p_{j, t}^{h}}$ due to unit elasticity, while domestic prices for domestic consumers remain unchanged ${ }^{27}$. The fiscal devaluation is made fiscally neutral through a lump sum transfer $\Gamma_{j, t}$ to households such that:

$$
\Gamma_{j, t}=\tau_{v, j, t}\left(\chi_{j} x_{b, j, t}+\left(1-\chi_{j}\right) x_{s, j, t}+g_{j, t}\right)-\tau_{v, j, t} w_{j, t} n_{j, t}
$$

so that the revenues from the VAT equal the cost of the payroll subsidy and the transfer. However, the indirect effects on income tax revenues that arise from the stimulative effects of a fiscal devaluation on output remain as would be the case of an exchange rate devaluation. The fiscal devaluation is applied starting in 2009. We set the VAT rate at $10 \%$ so that export volumes increase by the same amount. The increase in exports attenuates the fall in employment in all countries as shown in figure (14). Another effect of the fiscal devaluation is that the better employment figures induce governments to cut spending and transfers. Because of this and because of the stimulative effect of the fiscal devaluation on income taxes the trajectory of public debt is improved, as shown in figure (14). This improvement in the debt dynamics is quite large in all countries: in 2012 public debt is for example lower by around 20 percentage points of GDP in Ireland. This suggests that a condition for a successful fiscal adjustment is that countries can benefit from such a change in relative prices. In all countries, because of the reduction in public debt, funding costs are a bit lower.

\section{Conclusion}

Understanding the dynamics of the Eurozone is a major challenge for macroeconomics. Eurozone countries have experienced extraordinary levels of real and financial volatility. Unemployment rates have diverged to an extent that no one anticipated. While most observers recognize that private leverage, fiscal policy, sudden stops and loss of competitiveness all played a role, it has proven challenging to analyze them jointly, and even more difficult to disentangle them.

Our paper makes three contributions. We present a model that accounts simultaneously for domestic credit, fiscal policy, and current account dynamics. We create a data set for 11 countries over 13 years that covers the variables of interest and deals with the various accounting issues. Finally, and most importantly, we propose a new identification strategy that allows us to run counterfactual experiments regarding fiscal policy, macro-prudential policy, ECB interventions, and fiscal devaluations. The results from our counter-factual experiments on employment are summarized in Table 6. Stronger fiscal discipline during the boom would have made the recession less severe,

\footnotetext{
${ }^{27}$ Domestic prices and wages actually increase relative to data but only indirectly because of higher employment.
} 
especially in the case of Greece. A macro-prudential policy to limit private leverage during the boom would have helped to stabilize employment in all countries, and especially in Ireland. However, in the absence of a more prudent fiscal policy, this could have induced a larger buildup in public debt.

Table 6: Counter-Factual Employment Gains

\begin{tabular}{|c|c|c|c|c|}
\hline $2008-2012$ & ESP & GRE & IRL & PRT \\
\hline Actual Change in Employment & $-12.9 \%$ & $-15.8 \%$ & $-11.9 \%$ & $-6.6 \%$ \\
\hline \multicolumn{5}{|c|}{ Counter-Factual Gains } \\
\hline Conservative Fiscal Policy during Boom & $3.2 \%$ & $7.3 \%$ & $5.1 \%$ & $0 \%$ \\
\hline Macro-Prudential Policy during Boom & $4.1 \%$ & $3.4 \%$ & $7.7 \%$ & $1.7 \%$ \\
\hline No Financial Segmentation after 2008 & $3.4 \%$ & $12.4 \%$ & $4.6 \%$ & $4.0 \%$ \\
\hline Fiscal Devaluation (10\% in 2009 on) & $3.3 \%$ & $4.3 \%$ & $3.8 \%$ & $1.7 \%$ \\
\hline
\end{tabular}

Note: Spain lost 12.9 points of employment - more than the eurozone average - between 2008 and 2012. If Spain had run a successful macro-prudential policy during the boom, its employment would have been 4.1 points higher in 2012 , i.e. the drop would have been only $12.9-4.1=8.8$ points.

One lesson we take from this exercise is that fiscal and macro-prudential policies are complement rather than substitute when it comes to stabilizing the economy. In the case of Spain, the combination of conservative fiscal and macro-prudential policies would have meant a counter-factual gain of $13 \%$ of employment by 2012. A prudent fiscal policy, alone, would have generated a gain of $3.2 \%$. A macro-prudential policy alone would have generated a gain of $4.1 \%$. Both prudent fiscal policies and macro-prudential policies are therefore required to stabilize the economy. The sudden stop episode dramatically worsened the crisis by constraining governments during the bust. If the ECB had successfully reduced the spreads early in the crisis, the four countries would have been able to avoid fiscal austerity and the second half of the slump. However, this policy alone would not have avoided the large buildup in public debt. Finally, if those countries had been able to recoup competitiveness through a fiscal devaluation in 2009, the fall in employment would have been stabilized and fiscal austerity would have been successful in reducing public debt.

The contribution of our paper is to provide a coherent and quantitative framework to study the eurozone crisis. Our approach requires integrating various strands of the literature, which is difficult, but it allows us to consider a rich set of policies. On the other hand, the weakness of our analysis is that we are forced to treat some deep issues rather superficially. In our view, political economy issues and sovereign default decisions deserve a much deeper analysis. In our model, political economy issues are captured by a bias in the fiscal rules. This is certainly a useful starting point but it is not a satisfactory answer. For instance, Fernández Villaverde et al. (2013) argue that financial booms can lead to weaker monitoring and a deterioration in governance. Technically, this violates our identifying restriction since we assume that the political economy bias and the leverage boom do not affect each other directly. But more importantly it shows that we need a deeper understanding of the interaction between governments and financial markets. 
Similarly, we summarize sovereign default risk by a bond pricing equation. We are of course careful to estimate this equation with plausible instruments and to make sure that it fits well, which is critical for our experiments. But this clearly is not a satisfactory treatment of strategic sovereign default. Moreover, this approach does not help us to analyze reforms that would severe the link between sovereign risk and the private cost of funds. A sensible goal for the eurozone is to make sure that governments can default within the currency union and without destroying private financial markets. Understanding what is required to reach this goal is an important avenue for future research. 


\section{References}

Accominotti, O. and B. Eichengreen (2013). The mother of all sudden stops: Capital flows and reversals in europe, 1919-1932. Berkeley Economic History Laboratory Working Paper 2013/7.

Aguiar, M. and G. Gopinath (2007). Emerging market business cycles: the cycle is the trend. Journal of Political Economy 115, 69-102.

Arellano, C. (2008). Default risk and income fluctuations in emerging economies. American Economic Review 98(3), 690-712.

Battistini, N., M. Pagano, and S. Simonelli (2014, April). Systemic risk, sovereign yields and bank exposures in the euro crisis. Economic Policy 29(78), 203 - 251.

Bernanke, B., M. Gertler, and S. Gilchrist (1999). The financial accelerator in a quantitative business cycle framework. In J. B. Taylor and M. Woodford (Eds.), Handbook of Macroeconomics, Volume 1C. Elsevier Science, North Holland.

Bussiere, M., G. Callegari, F. Ghironi, G. Sestieri, and N. Yamano (2011). Estimating trade elasticities: Demand composition and the trade collapse of 2008-09. NBER Working Paper 17712.

Chari, V., P. Kehoe, and E. McGrattan (2005). Sudden stops and output drops. American Economic Review Papers and Proceedings 95(2), 381-387.

Chari, V. V., P. J. Kehoe, and E. R. McGrattan (2007, Oct). Business cycle accounting. Econometrica $75(3), 781-836$.

Christiano, Lawrence J., C. G. and J. Roldos (2004). Monetary policy in a financial crisis. Journal of Economic Theory 119, 1-245.

Cole, H. and M. Obstfeld (1991). Commodity trade and international risk sharing: How much do financial markets matter. Journal of Monetary Economics 28, 3-24.

Corsetti, G., K. Kuester, A. Meier, and G. J. Müller (2013). Sovereign risk, fiscal policy, and macroeconomic stability. Economic Journal (123), 99 - 132.

Cunat, V. and L. Garicano (2009). Did good cajas extend bad loans? governance, human capital and loan portfolios. FEDEA Monograph, "The Crisis of the Spanish Economy.

Cunat, V. and M. Guadalupe (2009). Executive compensation and competition in the banking and financial sectors. Journal of Banking and Finance 33, 439-474.

Eaton, J. and M. Gersovitz (1982). Debt with potential repudiation: Theoretical and empirical analysis. The Review of Economic Studies 48(2), 289-309.

ECB-HFCS (2013, April). The eurosystem household, finance and consumption survey, results from the first wave. Statistics Paper Series 2, European Central Bank.

Eggertsson, G. and P. Krugman (2012). Debt, deleveraging, and the liquidity trap:a fisher-minskykoo approach. Quarterly Journal of Economics (127(3)), 1469-1513.

Farhi, E., G. Gopinath, and O. Itskhoki (2014). Fiscal devaluations. Review of Economic Studies 81, $725-760$. 
Farhi, E. and I. Werning (2013). Fiscal multipliers: Liquidity traps and currency unions.

Favero, C. (2013). Modelling and forecasting government bond spreads in the euro area: a gvar model. Journal of Econometrics 117(2), 343-356.

Fernández Villaverde, J., L. Garicano, and T. Santos (2013). Political credit cycles: the case of the eurozone. Journal of Economc Perspectives 27(3), 145-66.

Franco, F. (2013). Fiscal devaluation in portugal. Mimeo.

Gali, J. (2008). Monetary Policy, Inflation, and the Business Cycle. Princeton University Press.

Gali, J. and T. Monacelli (2008). Optimal monetary and fiscal policy in a currency union. Journal of International Economics 76, 116-132.

Gertler, M. and N. Kiyotaki (2010). Financial intermediation and credit policy in business cycle analysis. Working Paper, NYU.

Giroud, X. and H. Mueller (2015). Firm leverage and unemployment during the great recession. mimeo NYU.

Gopinath, G. (2004). Lending booms, sharp reversals and real exchange rate dynamics. Journal of International Economics 62, 1-23.

Gourinchas, P.-O. and M. Obstfeld (2012). Stories of the twentieth century for the twenty-first. American Economic Journal Macro 4(1), 226-265.

Ivashina, V. and D. Scharfstein (2008). Bank lending during the financial crisis of 2008. Harvard Business School Working Paper.

Justiniano, A., G. Primiceri, and A. Tambalotti (2014). Credit supply and the housing boom. mimeo Northwestern.

Kaplan, G. and G. Violante (2011). A model of the consumption response to fiscal stimulus payments. mimeo NYU.

Kaplan, G., G. L. Violante, and J. Weidner (2014). The wealthy hand-to-mouth. Working Paper.

Kiyotaki, N. and J. Moore (1997, Apr). Credit cycles. Journal of Political Economy 105(2), 211-248.

Korinek, A. and E. G. Mendoza (2013). From sudden stops to fisherian deflation: Quantitative theory and policy implications. NBER WP 19362.

Lane, P. (2012). The european sovereign debt crisis. Journal of Economic Perspectives 26(3), 49-68.

Lane, P. (2013). Capital flows in the euro area. European Economy, Economic Papers $49 \%$.

Lee, D. and W. van der Klaauw (2012, November). An introduction to the frbny consumer credit panel. Federal Reserve Bank of New York Staff Reports.

Mankiw, N. G. (2000). The savers-spenders theory of fiscal policy. American Economic Review Papers and Proceedings, 120-125.

Martin, P. and H. Rey (2006). Globalization and emerging markets: With or without crash? American Economic Review vol 96, n5, 1631-51. 
Martinez, J. and T. Philippon (2014). Does a currency union need a capital market union? Working Paper, NYU.

Mendoza, E. G. (2010). Sudden stops, financial crises, and leverage. American Economic Review 100, 1941-1966.

Mendoza, E. G. and K. Smith (2006). Quantitative implications of a debt-deflation theory of sudden stops and asset prices. The Journal of International Economics Volume 70, Issue 1, 82-114.

Mendoza, E. G. and V. Z. Yue (2012). A general equilibrium model of sovereign default and business cycles. The Quarterly Journal of Economics 127, 889-946.

Mian, A. and A. Sufi (2010). Household leverage and the recession of 2007-2009. IMF Economic Review 1, 74-117.

Mian, A. and A. Sufi (2012). What explains high unemployment? the aggregate demand channel. Working Paper.

Midrigan, V. and T. Philippon (2010). Household leverage and the recession. NYU Working Paper.

Montoya, L. and B. Dohring (2011, October). The improbable renaissance of the phillips curve: The crisis and euro area inflation dynamics. European Commission Economic Paper.

Myers, S. C. (1977). Determinants of corporate borrowing. Journal of Financial Economics 5, $147-175$.

Nakamura, E. and J. Steinsson (2014). Fiscal stimulus in a monetary union: Evidence from u.s. regions. The American Economic Review.

Neumeyer, P. A. and F. Perri (2005). Business cycles in emerging economies: the role of interest rates. Journal of Monetary Economics 52(2), 345-380.

Philippon, T. and P. Schnabl (2013, February). Efficient recapitalization. Journal of Finance 68(1), 1-42. NBER WP 14929.

Reis, R. (2013, Spring). The portuguese slump and crash and the euro crisis. Brookings Papers on Economic Activity, 143-193.

Schmitt-Grohe, S. and M. Uribe (2012). Downward nominal wage rigidity, currency pegs, and involuntary unemployment. Working Paper.

Shambaugh, J. C. (2012, Spring). The euro's three crises. Brookings Papers on Economic Activity 212-219.

Whelan, K. (2014, March). Ireland's economic crisis: The good, the bad and the ugly. Journal of Macroeconomics. 


\section{A For Online Publication: Model and Simulation Appendix}

\section{A.1 Scaling}

We have already defined the Euler equations for country $j$ and the monetary union (with an asterisk):

$$
\mathbb{E}_{t}\left[X_{s, j, t+1}\right] \approx \beta\left(1+r_{j, t}\right) X_{s, j, t} ; \mathbb{E}_{t}\left[X_{s, t+1}^{*}\right] \approx \beta\left(1+r_{s, t}^{*}\right) X_{s, t}^{*}
$$

and the spread as

$$
1+\rho_{j, t} \equiv \frac{1+r_{j, t}}{1+r_{s, t}^{*}}
$$

If we scale the budget constraint (assuming perfect foresight, or equivalently, neglecting the conditional variance of the aggregate shocks), we get

$$
\frac{X_{s, j, t}}{X_{s, t}^{*}}+\frac{S_{j, t+1}}{X_{s, t+1}^{*}} \frac{\frac{X_{s, t+1}^{*}}{X_{s, t}^{*}}}{1+r_{j, t}}=\frac{S_{j, t}}{X_{s, t}^{*}}+\frac{\tilde{Y}_{j, t}}{X_{s, t}^{*}}
$$

and up to the usual approximation we have

$$
x_{s, j, t}+\frac{\beta}{1+\rho_{j, t}} s_{j, t+1}=s_{j, t}+\tilde{y}_{j, t}
$$

For the Phillips Curve we start from (12) and the equivalent equation at the eurozone level:

$$
\frac{W_{t}^{*}}{W_{t-1}^{*}}=\left(\frac{N_{t}^{*}}{\bar{N}^{*}}\right)^{\kappa}
$$

Then we define

$$
n_{j, t} \equiv \frac{N_{j, t} / \bar{N}_{j}}{N_{t}^{*} / \bar{N}^{*}} \text { and } w_{j, t} \equiv \frac{W_{j, t}}{W_{j, t}^{*}} .
$$

To a first order approximation we then have

$$
\frac{w_{j, t}}{w_{j, t-1}}=1+\kappa\left(n_{j, t}-1\right)
$$

Notice that this kind of log linear relation would hold even if the aggregate wage has a forward looking component so in fact we only need to assume that the country specific component follows (12). ${ }^{28}$ Since

$$
n_{j, t}=\frac{y_{j, t}}{w_{j, t}}
$$

we have

$$
\frac{\left(w_{j, t}\right)^{2}}{w_{j, t-1}}+(\kappa-1) w_{j, t}-\kappa y_{j, t}=0
$$

\footnotetext{
${ }^{28}$ In logs, we can write $\log W_{j t}=\log W_{j t}^{*}+\log w_{j t}$. For the aggregate component we can then write: $\log W_{j t}^{*}=$ $\zeta \mathbb{E}_{t} \log W_{j t+1}^{*}+(1-\zeta) \log W_{j t-1}^{*}+\kappa^{*}\left(\log N_{t}^{*}-\log \bar{N}^{*}\right)$, where $\zeta$ captures the kind of hybrid Phillips curve that many people have estimated. In particular, our model is perfectly consistent with the idea that monetary policy can influence expected inflation at the aggregate level. We only assume that the country specific component follows: $\log w_{j t}=\log w_{j t-1}+\kappa \log n_{j t}$. We have also estimated a country specific forward looking component but found it to be insignificant. For the sake of simplicity we therefore omit it.
} 
Defining $\Delta \equiv(\kappa-1)^{2}+4 \kappa \frac{y_{j, t}}{w_{j, t-1}}$, we find that

$$
\frac{w_{j, t}}{w_{j, t-1}}=\frac{1-\kappa+\sqrt{\Delta}}{2}
$$

Note that if $\frac{y_{j, t}}{w_{j, t-1}}=1$, then $\Delta=(\kappa+1)^{2}$, and $\frac{w_{j, t}}{w_{, t-1}}=1$.

\section{A.2 Budget constraints}

Let us first rewrite the budget constraints and market clearing conditions. Using the market clearing condition, and competition $p_{j, t}^{h}=w_{j, t}$, we get

$$
y_{j, t}=\alpha_{j}\left(\chi_{j} x_{b, j, t}+\left(1-\chi_{j}\right) x_{s, j, t}\right)+f_{j, t}+g_{j, t}
$$

Nominal exports are $f_{j, t}$, nominal imports are $\left(1-\chi_{j}\right) p_{j, t}^{f} c_{s, j, t}^{f}+\chi_{j} p_{j, t}^{f} c_{b, j, t}^{f}$ since the government does not buy imported goods. So net exports are $e_{j, t}=f_{j, t}-\left(1-\alpha_{j}\right)\left(\chi_{j} x_{b, j, t}+\left(1-\chi_{j}\right) x_{s, j, t}\right)$. We define disposable (after-tax) income as $\tilde{y}_{j, t} \equiv\left(1-\tau_{j, t}\right) y_{j, t}+z_{j, t}$.

We can then write the system for nominal variables

- $x_{b, j, t}=\frac{\beta}{1+\rho_{j, t}} b_{j, t+1}^{h}+\tilde{y}_{j, t}-b_{j, t}^{h}$, budget constraint of impatient agents

- $x_{s, j, t}=s_{j, t}+\tilde{y}_{j, t}-\frac{\beta}{1+\rho_{j, t}} s_{j, t+1}$, budget constraint of patient agents

- $y_{j, t}=\alpha_{j}\left(\chi_{j} x_{b, j, t}+\left(1-\chi_{j}\right) x_{s, j, t}\right)+f_{j, t}+g_{j, t}$, market clearing

- $g_{j, t}+z_{j, t}-\tau_{j, t} y_{j, t}=\frac{\beta}{1+\rho_{j, t}} b_{j, t+1}^{g}-b_{j, t}^{g}$, budget constraint of the government

- $e_{j, t}=\frac{1}{\alpha_{j}}\left(f_{j, t}-\left(1-\alpha_{j}\right)\left(y_{j, t}-g_{j, t}\right)\right)$, definition of net exports

Combining the first four equations, we get market clearing at time $t$ :

$$
\left(1-\alpha_{j}\right) \tilde{y}_{j, t}=\alpha_{j} \chi_{j}\left(\beta \frac{b_{j, t+1}^{h}}{1+\rho_{j, t}}-b_{j, t}^{h}\right)+\alpha_{j}\left(1-\chi_{j}\right)\left(s_{j, t}-\beta \frac{s_{j, t+1}}{1+\rho_{j, t}}\right)+\beta \frac{b_{j, t+1}^{g}}{1+\rho_{j, t}}-b_{j, t}^{g}+f_{j, t} .
$$

\section{A.3 Pseudo-Steady State}

We consider a steady state with constant interest rates equal to the rate of time preference of savers, i.e. $\beta\left(1+r_{j}\right)=1$ and the spread is zero: $\rho_{j}=0$. The borrowing limit $b_{j}^{h}$ is exogenous and we consider equilibria where the borrowing constraint (4) binds. Our notion of steady state is complicated by the fact that savings $s_{j}$ are history-dependent. We define a steady state as the long run equilibrium of an economy with initial savings $s_{j}$ and government debt $b_{j}^{g}$, subject to no further shocks, constant government spending and constant government debt. All nominal quantities are 
constant and employment is at its natural rate $\bar{n} \cdot{ }^{29}$ The long-run equilibrium conditions are

$$
\begin{aligned}
p_{j}^{h} \bar{n} & =\chi_{j} \alpha_{j} x_{b, j}+\left(1-\chi_{j}\right) \alpha_{j} x_{s, j}+f+g_{j} \\
x_{b, j} & =\tilde{y}_{j}-\frac{r}{1+r} b_{j}^{h} \\
x_{s, j} & =\tilde{y}_{j}+\frac{r}{1+r} s_{j} \\
\tau_{j} p_{j}^{h} \bar{n} & =g_{j}+z_{j}+\frac{r}{1+r} b_{j}^{g}
\end{aligned}
$$

Nominal output (the price of home goods) is pinned down by

$$
p_{j}^{h} \bar{n}=\alpha_{j}\left(\left(1-\tau_{j}\right) p_{j}^{h} \bar{n}+z_{j}\right)+\alpha_{j} \frac{r}{1+r}\left(\left(1-\chi_{j}\right) s_{j}-\chi_{j} \bar{b}_{j}\right)+f_{j}+g_{j}
$$

There are several ways to specify government policy. Here we assume that the policy is to keep government debt and nominal spending $g_{j}$ constant. Long run nominal output is then given by

$$
p_{j}^{h} \bar{n}=\frac{\alpha_{j}}{1-\alpha_{j}} r a_{j}+\frac{f_{j}}{1-\alpha_{j}}+g_{j}
$$

where recall that we have defined $a$ as net foreign assets. This equation shows the determinants of the long run price level. The long run price level depends on the exogenous components of spending: net asset income, foreign demand, and government spending. All these are inflationary. For a given tax rate $\tau_{j}$, transfers are then chosen to satisfy the government's budget constraint:

$$
z_{j}=\tau_{j} p_{j}^{h} \bar{n}-g_{j}-\frac{r}{1+r} b_{j}^{g} .
$$

\section{A.4 Euler Equation and Expected Income}

We use a linear approximation of the Euler equation of savers:

$$
\mathbb{E}_{t}\left[x_{s, j, t+1}\right]=\left(1+\rho_{j, t}\right) x_{s, j, t} .
$$

Consider the following experiment. Savers enter the period with a given level of savings. Then there is a shock to interest rates. For instance, starting from a steady state where $\rho_{j}=0$, if the new rate is such that $\rho_{j}>0$, savings jumps up, and if the new rate is such that $\rho_{j}<0$, spending jumps up. The budget constraint at time $t$ is

$$
x_{s, j, t}=s_{j, t}+\tilde{y}_{j, t}-\beta \frac{s_{j, t+1}}{1+\rho_{j, t}}
$$

and the expected budget constraint at time $t+1$ is

$$
\mathbb{E}_{t}\left[\beta \frac{s_{j, t+2}}{1+\rho_{j, t+1}}\right]=s_{j, t+1}+\mathbb{E}_{t}\left[\tilde{y}_{j, t+1}-x_{s, j, t+1}\right] .
$$

Combining the budget constraints and the linearized Euler equation, we get

$$
(1+\beta) s_{j, t+1}+\mathbb{E}_{t}\left[\tilde{y}_{j, t+1}\right]-\mathbb{E}_{t}\left[\beta \frac{s_{j, t+2}}{1+\rho_{j, t+1}}\right]=\left(1+\rho_{j, t}\right)\left(s_{j, t}+\tilde{y}_{j, t}\right) .
$$

\footnotetext{
${ }^{29}$ We consider here the case where labor supply is inelastic, so $\bar{n}$ is effectively exogenous.
} 


\section{A.5 Equilibrium Conditions of the Model}

We assume an $\mathrm{AR}(1)$ process for the spread:

- $\mathbb{E}_{t}\left[\rho_{j, t+1}\right]=\theta \rho_{j, t}$, spreads

The equilibrium conditions are then

- $\mathbb{E}_{t}\left[x_{s, j, t+1}\right]=\left(1+\rho_{j, t}\right) x_{s, j, t}$, Euler equation

- $x_{b, j, t}=\frac{\beta}{1+\rho_{j, t}} b_{j, t+1}^{h}+\tilde{y}_{j, t}-b_{j, t}^{h}$, budget constraint of impatient agents

- $x_{s, j, t}=s_{j, t}+\tilde{y}_{j, t}-\frac{\beta}{1+\rho_{j, t}} s_{j, t+1}$, budget constraint of patient agents

- $y_{j, t}=\alpha_{j}\left(\chi_{j} x_{b, j, t}+\left(1-\chi_{j}\right) x_{s, j, t}\right)+f_{j, t}+g_{j, t}$, market clearing

- $g_{j, t}+z_{j, t}-\tau_{j, t} y_{j, t}=\beta \frac{b_{j, t+1}^{g}}{1+\rho_{j, t}}-b_{j, t}^{g}$, budget constraint of the government

- $e_{j, t}=\frac{1}{\alpha_{j}}\left(f_{j, t}-\left(1-\alpha_{j}\right)\left(y_{j, t}-g_{j, t}\right)\right)$, net exports

- $\tilde{y}_{j, t}=\left(1-\tau_{j}\right) y_{j, t}+z_{j, t}$, disposable income

- $s_{j, t+1}=\left(1+\rho_{j, t}\right)\left(s_{j, t}+\tilde{y}_{j, t}\right)-\frac{1-\beta \theta\left(1+\rho_{j, t}\right)}{1-\beta \theta} \mathbb{E}_{t}\left[\tilde{y}_{j, t+1}\right]$, saving dynamics

- $\left(1-\alpha_{j}\right) \tilde{y}_{j, t}=\alpha_{j} \chi_{j}\left(\beta \frac{b_{j, t+1}^{h}}{1+\rho_{j, t}}-b_{j, t}^{h}\right)+\alpha_{j}\left(1-\chi_{j}\right)\left(s_{j, t}-\beta \frac{s_{j, t+1}}{1+\rho_{j, t}}\right)+\beta \frac{b_{j, t+1}^{g}}{1+\rho_{j, t}}-b_{j, t}^{g}+f_{j, t}$, market clearing

- $\left(1-\alpha_{j}+\alpha_{j}\left(\left(1-\chi_{j}\right) \frac{\beta \theta}{1-\beta \theta} \rho_{j, t}\right)\right) \mathbb{E}_{t}\left[\tilde{y}_{j, t+1}\right]=(1-\beta)\left(\alpha_{j}\left(1-\chi_{j}\right) s_{j, t+1}-\alpha_{j} \chi_{j} b_{j, t+1}^{h}-b_{j, t+1}^{g}\right)+$ $f_{j, t}-\theta \beta \rho_{j, t}\left(\alpha_{j} \chi_{j} b_{j, t+1}^{h}+b_{j, t+1}^{g}\right)$, expected market clearing

- $n_{j, t}=\frac{y_{j, t}}{w_{j, t}}$, labor market

- $\frac{w_{j, t}-w_{j, t-1}}{w_{j, t-1}}=\kappa\left(n_{j, t}-\bar{n}_{j}\right)$, inflation

\section{A.6 Impulse Response Functions}

To compute the impulse response functions of the model we need to make an assumption about the path of household debt and fiscal policy

\section{Assumptions A1.}

- Shocks on borrowing constraints are such that $\mathbb{E}_{t}\left[b_{j, t+2}^{h}\right]=b_{j, t+1}^{h}$.

- Fiscal policy is such that $\mathbb{E}_{t}\left[b_{j, t+2}^{g}\right]=b_{j, t+1}^{g}$ and the tax rate $\tau_{j}$ is constant.

- The variance of interest rates and foreign demand is small, and $\beta_{b}$ is small enough that $b_{j, t}=$ $b_{j, t}^{h}$ at all times.

- Spreads are iid: $\mathbb{E}_{t}\left[\rho_{j, t+1}\right]=0$. Savers anticipate spreads to last only one year. 
Assumptions A1 are only necessary to solve for the entire path of macroeconomic variables shown in the impulse response functions. The first condition says that shocks on borrowing are permanent. The second defines a class of fiscal policies. The third point is purely technical. It allows us to linearize Euler equations. We assume that the shocks are small enough that impatient households find it optimal to borrow up to the constraint (this is a joint restriction on the discount factor and the size of the shocks). Note that the last assumption does not impose that the interest rate in the monetary union is iid, only that deviations for a particular country are expected to last one year. Assumptions A1 are not necessary for the reduced form and structural simulations.

We now look for decision rules for the savers $\left\{s_{j, t}\right\}_{t=1,2 \ldots}$ and the other variables of the model, $y_{j, t}, p_{j, t}^{h}$, etc. We get the following Lemma:

Lemma 1. Under $A 1$ and $\mathbb{E}_{t}\left[f_{j, t+1}\right]=f_{j, t}$ savings dynamics satisfy $\mathbb{E}_{t}\left[s_{j, t+2}\right]=s_{j, t+1}$.

Proof. We guess and verify that the Lemma is correct. Suppose the Lemma is true, then we obtain two important equations. Equation (24) becomes

$$
s_{j, t+1}=\left(1+\rho_{j, t}\right)\left(s_{j, t}+\tilde{y}_{j, t}\right)-\mathbb{E}_{t}\left[\tilde{y}_{j, t+1}\right],
$$

and expected market clearing at $t+1$ is

$$
\left(1-\alpha_{j}\right) \mathbb{E}_{t}\left[\tilde{y}_{j, t+1}\right]=(1-\beta)\left(\alpha_{j}\left(1-\chi_{j}\right) s_{j, t+1}-\alpha_{j} \chi b_{j, t+1}^{h}-b_{j, t+1}^{g}\right)+f_{j, t} .
$$

Therefore

$$
\left(1-\alpha_{j}\right) s_{j, t+1}=\left(1-\alpha_{j}\right)\left(1+\rho_{j, t}\right)\left(s_{j, t}+\tilde{y}_{j, t}\right)-(1-\beta)\left(\alpha_{j}\left(1-\chi_{j}\right) s_{j, t+1}-\alpha_{j} \chi b_{j, t+1}^{h}-b_{j, t+1}^{g}\right)-\frac{f_{j, t}}{1-\alpha_{j}} .
$$

Using market clearing at time $t$ we get

$$
\frac{s_{j, t+1}}{1+\rho_{j, t}}-s_{j, t}=\frac{\alpha_{j} \chi_{j}}{1-\alpha_{j} \chi_{j}}\left(\frac{b_{j, t+1}^{h}}{1+\rho_{j, t}}-b_{j, t}^{h}\right)+\frac{1}{1-\alpha_{j} \chi_{j}}\left(\frac{b_{j, t+1}^{g}}{1+\rho_{j, t}}-b_{j, t}^{g}+\frac{\rho_{j, t}}{1+\rho_{j, t}} \frac{f_{j, t}}{1-\alpha_{j}}\right)
$$

Savings inherit the dynamic properties of $b_{j, t}^{h}$ and $b_{j, t}^{g}$. Since we assume small shocks and $\mathbb{E}_{t}\left[\rho_{j, t+1}\right]=$ 0 , this validates our conjecture that $\mathbb{E}_{t}\left[s_{j, t+2}\right]=s_{j, t+1}$.

Equilibrium conditions The five equilibrium conditions of the model with $\theta=0$ are

1. $s_{j, t+1}=\left(1+\rho_{j, t}\right)\left(s_{j, t}+\tilde{y}_{j, t}\right)-\mathbb{E}_{t}\left[\tilde{y}_{j, t+1}\right]$

2. $\left(1-\alpha_{j}\right) \mathbb{E}_{t}\left[\tilde{y}_{j, t+1}\right]=(1-\beta)\left(\alpha_{j}\left(1-\chi_{j}\right) s_{j, t+1}-\alpha_{j} \chi_{j} b_{j, t+1}^{h}-b_{j, t+1}^{g}\right)+f_{j, t}$.

3. $\left(1-\alpha_{j}\right) \tilde{y}_{j, t}=\alpha_{j} \chi_{j}\left(\frac{b_{j, t+1}^{h}}{1+r_{j, t}}-b_{j, t}^{h}\right)+\alpha_{j}\left(1-\chi_{j}\right)\left(s_{j, t}-\beta \frac{s_{j, t+1}}{1+\rho_{j, t}}\right)+\beta \frac{b_{j, t+1}^{g}}{1+\rho_{j, t}}-b_{j, t}^{g}+f_{j, t}$.

4. $g_{j, t}+z_{j, t}-\tau_{j} y_{j, t}=\beta \frac{b_{j, t+1}^{g}}{1+\rho_{j, t}}-b_{j, t}^{g}$

5. $\tilde{y}_{j, t}=\left(1-\tau_{j}\right) y_{j, t}+z_{j, t}$

The five unknown endogenous variables are $\tilde{y}_{j, t}, y_{j, t}, b_{j, t}^{g}, s_{j, t+1}$, and $\mathbb{E}_{t}\left[\tilde{y}_{j, t+1}\right]$. The exogenous shocks are $b_{j, t}^{h}, f_{j, t}$ and $\rho_{j, t}$. The policy shocks variables are transfers and public expenditure, $z_{j, t}$ and $g_{j, t}$ respectively. The state space of predetermined endogenous variables is $s_{j, t}$ and $b_{j, t}^{g}$. 
We specify the policy function of the government in order to compute the impulse responses. We are interested in simple rules that deliver the property that the public debt follows a random walk: $\mathbb{E}_{t}\left[b_{j, t+2}^{g}\right]=b_{j, t+1}^{g}$ and deliver some automatic stabilization. We assume that spending and transfers are predetermined. From the government budget constraint, this means that a recession at time $t$ automatically increases government debt at time $t$. To maintain fiscal stability, we specify that transfers adjust from $t$ to $t+1$ to keep public debt constant thereafter: $\mathbb{E}_{t}\left[b_{j, t+2}^{g}\right]=b_{j, t+1}^{g}$. More precisely, we specify the general policy rule as follows

1. Fiscal variables $g_{j, t}$ and $z_{j, t}$ are pre-determined. Government debt $b_{j, t}^{g}$ is determined in equilibrium at time $t$.

2. Set transfers $z_{j, t+1}$ for next period so that $\mathbb{E}_{t}\left[b_{j, t+2}^{g}\right]=b_{j, t+1}^{g}$ assuming a martingale for $g_{j, t}$.

(a) The expected budget constraint is

$$
\tau_{j} \mathbb{E}_{t}\left[y_{j, t+1}\right]=g_{j, t}+z_{j, t+1}+(1-\beta) b_{j, t+1}^{g}
$$

(b) By definition we have

$$
\mathbb{E}_{t}\left[\tilde{y}_{j, t+1}\right]=\left(1-\tau_{j}\right) \mathbb{E}_{t}\left[y_{j, t+1}\right]+z_{j, t+1}
$$

(c) Therefore (recall that $\mathbb{E}_{t}\left[\tilde{y}_{j, t+1}\right]$ is part of our solution at time $t$ ), $z_{j, t+1}$ is given by

$$
z_{j, t+1}=\tau_{j} \mathbb{E}_{t}\left[\tilde{y}_{j, t+1}\right]-\left(1-\tau_{j}\right) g_{j, t}-\left(1-\tau_{j}\right)(1-\beta) b_{j, t+1}^{g}
$$

Figures (15), (16) and (17) illustrate the impulse response functions of the model for a shock to household debt $\left(b_{j, t}^{h}\right)$, public spending $\left(g_{j, t}\right)$, interest rates $\left(r_{j, t}\right)$ and foreign demand $\left(f_{j, t}\right)$ respectively.

Figure 15: Fiscal Expansion
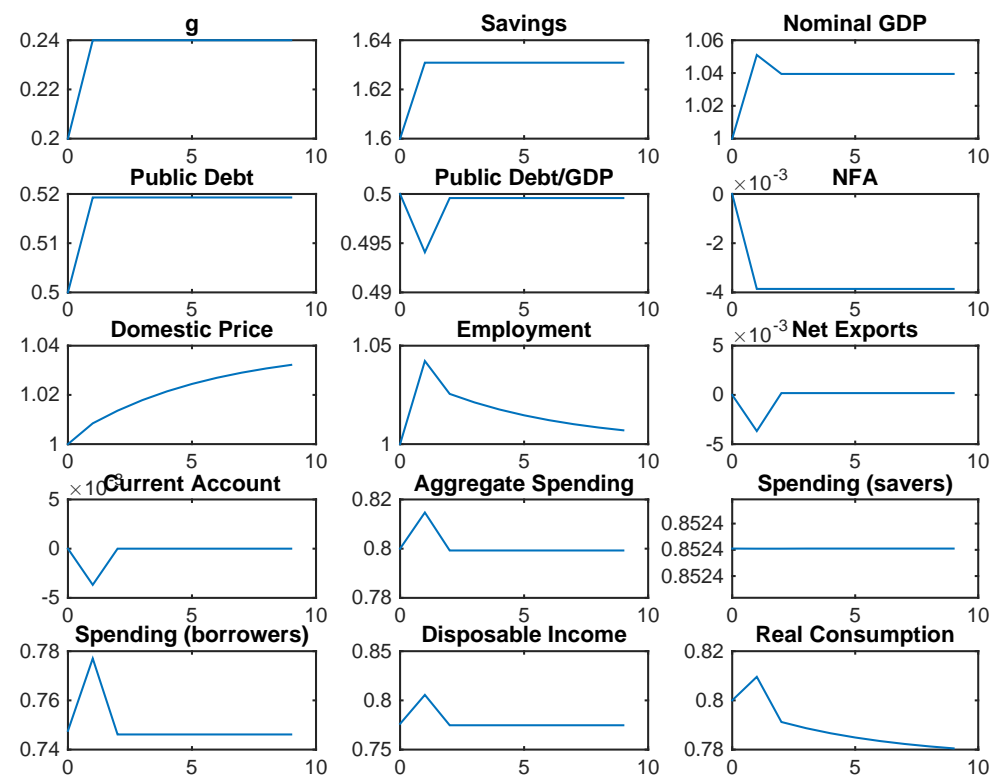
Figure 16: Interest Rate Shock
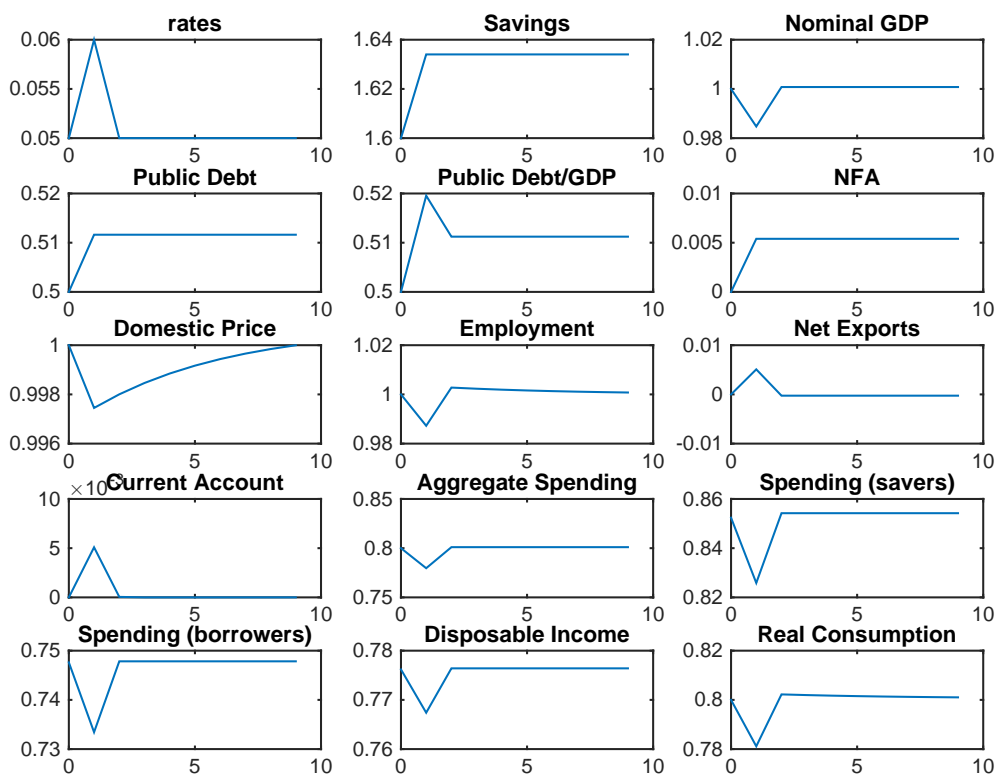

Figure 17: Foreign Demand Shock
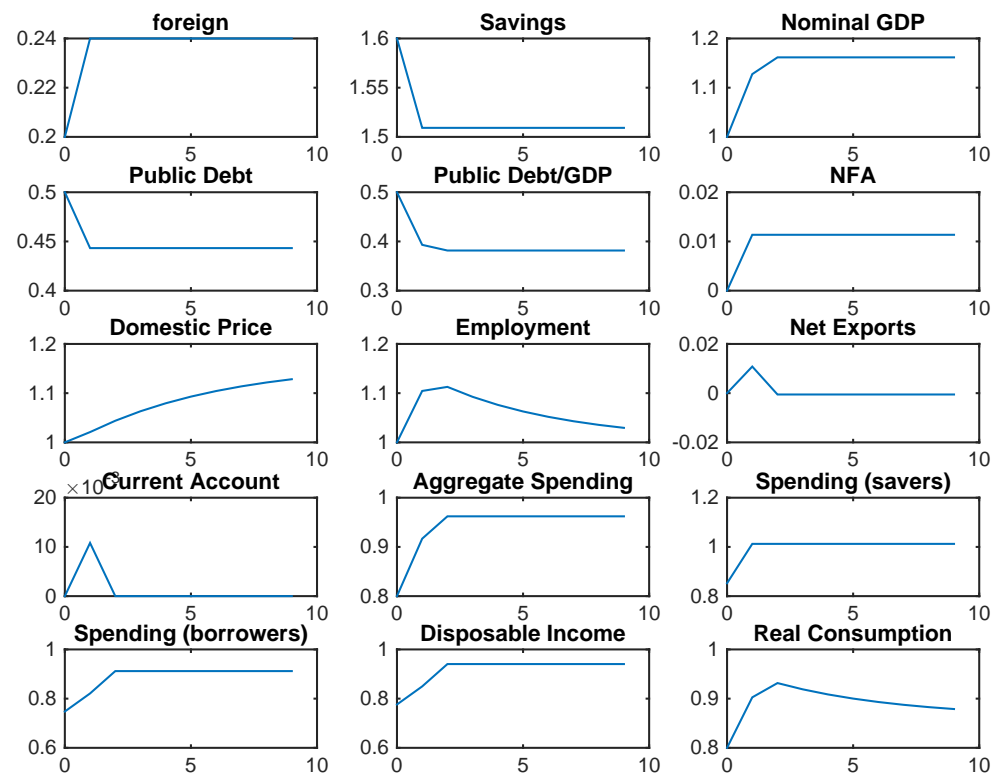

\section{A.7 Simulation of the reduced form and structural models}

To run the simulations, we first need to set the initial conditions in a particular year. We use 2002 as our base year $t_{0}$. 
1. Natural employment and prices (which are equal to wages) are normalized to $n^{\star}=1$ and $p_{j, t_{0}}^{h}=1$ (so nominal GDP is normalized in the base year to: $y_{j, t_{0}}=1$ )

2. Variables set to their observed values are: $b_{j, t_{0}}^{h}, z_{j, t_{0}}, g_{j, t_{0}}, b_{j, t_{0}}^{g}, b_{j, t_{0}-1}^{g}, r_{j, t_{0}}$. We then get $f_{j, t_{0}}$, $\tau_{j}$ and $\tilde{y}_{j, t_{0}}$ from market clearing and budget constraints:

(a) Foreign demand $f_{j, t_{0}}$ is chosen to match net exports $e_{j, t_{0}}=\frac{1}{\alpha_{j}}\left(f_{j, t_{0}}-\left(1-\alpha_{j}\right)\left(y_{j, t_{0}}-g_{j, t_{0}}\right)\right)$

(b) We get $\tau_{j}$ from the government budget constraint $g_{j, t_{0}}+z_{j, t_{0}}-\tau_{j} y_{j, t_{0}}=\frac{b_{j, t_{0+1}}^{g}}{1+r_{j, t_{0}}}-b_{j, t_{0}}^{g}$

(c) Disposable income at time $t_{0}$ is $\tilde{y}_{j, t_{0}}=\left(1-\tau_{j}\right) y_{j, t_{0}}+z_{j, t_{0}}$

3. Savers' assets $s_{j, t_{0}}$ and $s_{j, t_{0}-1}$ are chosen to solve the equilibrium conditions

(a) $s_{j, t+1}=\left(1+\rho_{j, t}\right)\left(s_{j, t}+\tilde{y}_{j, t}\right)-\frac{1-\beta \theta\left(1+\rho_{j, t}\right)}{1-\beta \theta} \mathbb{E}_{t}\left[\tilde{y}_{j, t+1}\right]$

(b) $\left(1-\alpha_{j}+\alpha_{j}\left(\left(1-\chi_{j}\right) \frac{\beta \theta}{1-\beta \theta} \rho_{j, t}\right)\right) \mathbb{E}_{t}\left[\tilde{y}_{j, t+1}\right]=(1-\beta)\left(\alpha_{j}\left(1-\chi_{j}\right) s_{j, t+1}-\alpha_{j} \chi_{j} b_{j, t+1}^{h}-b_{j, t+1}^{g}\right)+$ $f_{j, t}-\theta \beta \rho_{j, t}\left(\alpha_{j} \chi_{j} b_{j, t+1}^{h}+b_{j, t+1}^{g}\right)$.

(c) $\left(1-\alpha_{j}\right) \tilde{y}_{j, t}=\alpha_{j} \chi_{j}\left(\beta \frac{b_{j, t+1}^{h}}{1+\rho_{j, t}}-b_{j, t}^{h}\right)+\alpha_{j}\left(1-\chi_{j}\right)\left(s_{j, t}-\beta \frac{s_{j, t+1}}{1+\rho_{j, t}}\right)+\beta \frac{b_{j, t+1}^{g}}{1+\rho_{j, t}}-b_{j, t}^{g}+f_{j, t}$.

For the reduced form model, we then feed exogenous processes for the different shocks (using scales values) for observed household debt $\left(b_{j, t}^{h}\right)$, fiscal policy $\left(\tau_{j}, z_{j, t}, g_{j, t}\right)$, interest rate spreads $\rho_{j, t}$ and foreign nominal demand shocks $f_{j, t}$. For each country, we simulate the path between 2001 and 2012 of nominal GDP $y_{j, t}$, employment $n_{j, t}$, wages $w_{j, t}$, net exports $e_{j, t}$ and public debt $b_{j, t}^{g}$.

The level of output, the price level and the level of net foreign assets is set to their 2002 levels in the data. Foreign demand is set using data on exports in value added terms for 2001-2012, normalized so that the level of foreign demand in 2002 satisfies goods market clearing in the model. Finally, taxes are set so that the path for government debt implied by the model coincides with the data. $^{30}$

Figures (4) in the main text, (18) and (19) show the simulated (reduced form) and observed nominal GDP, employment and wages. For all the simulated variables, we add the difference between the mean of the data and the mean of the simulated model as the base year (2002) which serves to scale the data and model is somewhat arbitrary.

\footnotetext{
${ }^{30}$ Instead of using government debt directly from data, we construct a simulated government debt series in order to avoid including factors that affect government debt in the data but are not in the model, such as bank recapitalizations, default, revenues from privatizations, etc. The simulated debt series is constructed by adding to $t-1$ period debt government expenditures including interest payments and subtracting tax revenues.
} 
Figure 18: Reduced Form Model, Employment
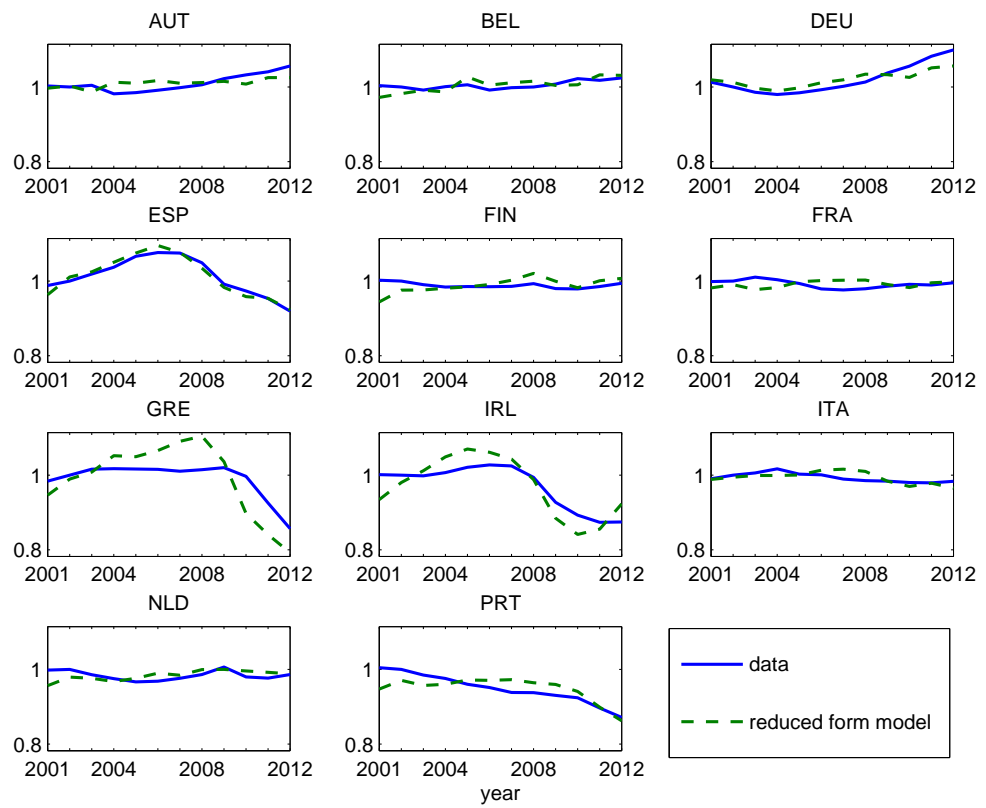

Figure 19: Reduced Form Model, Wages
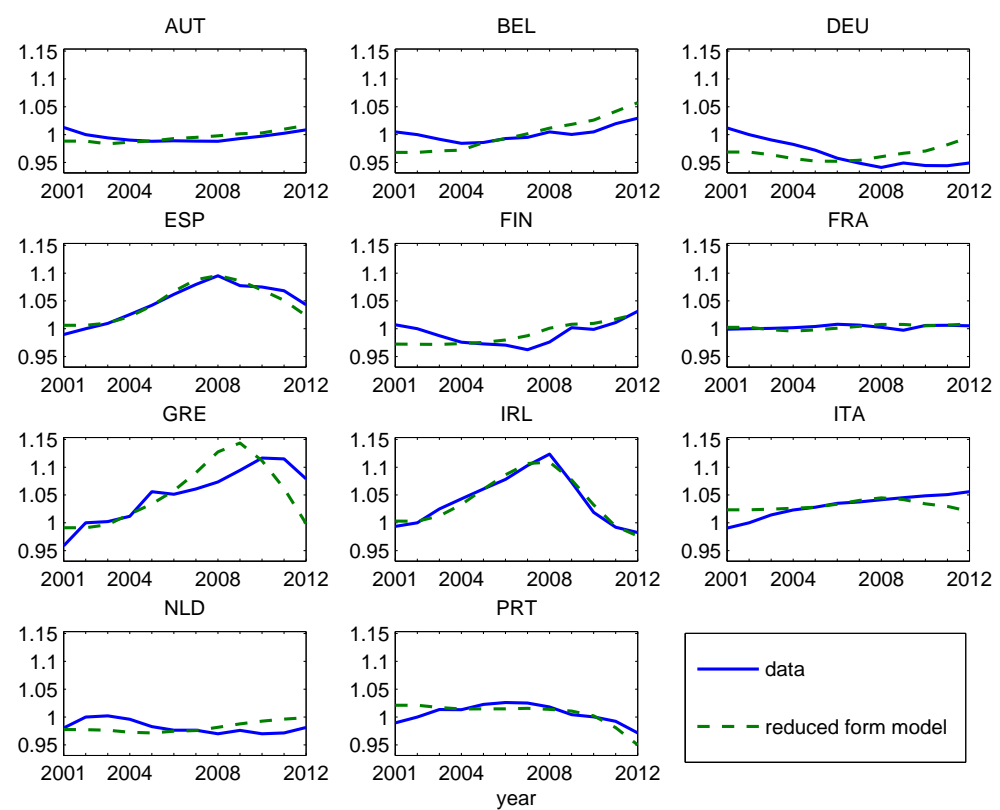

$\longrightarrow$ data

- - - reduced form model 
The structural model is simulated in the same way but the exogenous variables are replaced by structural equations (17) and (18) for private debt and spreads respectively and the fiscal policy rule (19). The tax rate is constant at its 2002 level and equal to total government revenues as a percentage of GDP. The structural shocks are now $\hat{b}_{j, t}^{h}, \sigma_{t}, \tilde{g}_{j, t}$. and $\tilde{z}_{j, t}$. In addition to the comparison of the actual and predicted (with the structural model) series for nominal GDP and employment in figure (6), public debt and funding costs in figure (7) in the main text, we show observed and simulated net exports in figure (20).

Figure 20: Structural Model, Net Exports
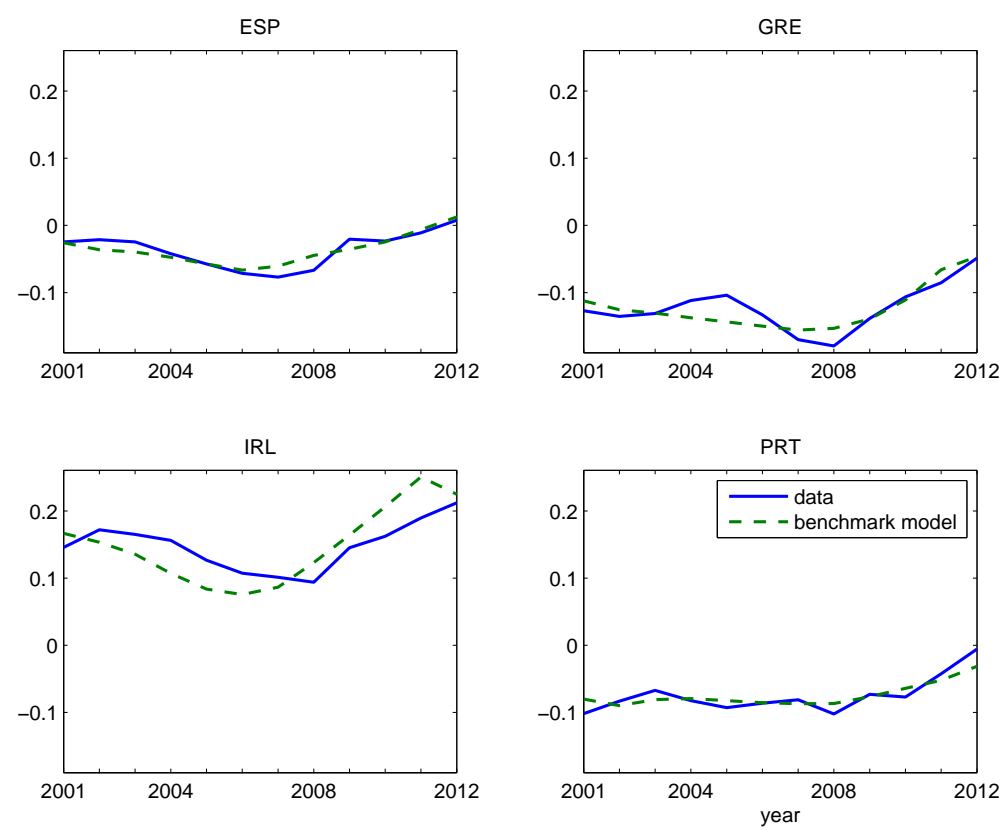

\section{A.8 Fiscal Devaluation}

We define a fiscal devaluation as the combination of a VAT tax on domestic expenditures (private and public) and a payroll subsidy. Let $p_{j, t}^{h}$ be the price of home goods for domestic consumers, and $p_{j, t}^{*}$ be the price of home goods for foreign consumers. $\tau_{v, j, t}$ is the VAT so that the government collects $\tau_{v, j, t}\left(\chi_{j} x_{b, j, t}+\left(1-\chi_{j}\right) x_{s, j, t}+g_{j, t}\right)$. The VAT is paid by firms and rebated to exporters. $\lambda_{j, t}$ is the payroll subsidy so the government pays $\lambda_{j, t} w_{j, t} n_{j, t}$ to firms. Profit maximization implies the following prices:

$$
\left(1-\tau_{v, j, t}\right) p_{j, t}^{h}=p_{j, t}^{*}=\left(1-\lambda_{j, t}\right) w_{j, t},
$$

and foreign demand becomes $\frac{f_{j, t}}{\left(1-\tau_{v, j, t}\right) p_{j, t}^{h}}$. Given that the VAT is imposed on imported goods, importers (assuming flexible prices for foreign firms as for domestic firms) increase the price of their imports to compensate for the VAT, so we have $p_{j, t}^{f}=\frac{p_{t}^{f}}{1-\tau_{v, j, t}}$ where $p_{j, t}^{f}$ is the domestic price of foreign goods in country $j$ and $p_{t}^{f}$ is the foreign price of foreign goods. With log preferences, this leads to a one for one drop in the quantity of imported foreign goods, while the spending shares remain the same. For simplicity we further assume that the VAT rate and payroll subsidies are 
equal, $\tau_{v, j, t}=\lambda_{j, t}$ so that $p_{j, t}^{h}=w_{j, t}, y_{j, t}=w_{j, t} n_{j, t}=p_{j, t} n_{j, t}$ and domestic prices to domestic consumers are unchanged. We also assume $\mathbb{E}_{t}\left[\tau_{v, j, t+1}\right]=\tau_{v, j, t}$. The government budget constraint, is then:

$$
\beta \frac{b_{j, t+1}^{g}}{1+\rho_{j, t}}+\left(\tau_{j, t}-\tau_{v, j, t}\right) w_{j, t} n_{j, t}+\tau_{v, j, t}\left(\chi_{j} x_{b, j, t}+\left(1-\chi_{j}\right) x_{s, j, t}+g_{j, t}\right)=g_{j, t}+z_{j, t}+\Gamma_{j, t}+b_{j, t}^{g},
$$

where $\Gamma_{j, t}$ is a lump sum transfer to households. We set this transfer so that the fiscal devaluation is neutral for the government budget constraint in the sense that the budget constraint remains:

$$
\beta \frac{b_{j, t+1}^{g}}{1+\rho_{j, t}}+\tau_{j, t} y_{j, t}=g_{j, t}+z_{j, t}+b_{j, t}^{g},
$$

so the lump sum transfer is:

$$
\Gamma_{j, t}=\tau_{v, j, t}\left(\chi_{j} x_{b, j, t}+\left(1-\chi_{j}\right) x_{s, j, t}+g_{j, t}\right)-\tau_{v, j, t} w_{j, t} n_{j, t} .
$$

Market clearing becomes:

$$
n_{j, t}=\alpha_{j} \frac{\chi_{j} x_{b, j, t}+\left(1-\chi_{j}\right) x_{s, j, t}}{p_{j, t}^{h}}+\frac{f_{j, t}}{\left(1-\tau_{v, j, t}\right) p_{j, t}^{h}}+\frac{g_{j, t}}{p_{j, t}^{h}}
$$

and budget constraints are

$$
x_{b, j, t}=\beta \frac{b_{j, t+1}^{h}}{1+\rho_{j, t}}+\tilde{y}_{j, t}-b_{j, t}^{h} \quad ; \quad x_{s, j, t}=s_{j, t}+\tilde{y}_{j, t}-\beta \frac{s_{j, t+1}}{1+\rho_{j, t}}
$$

where net income is now defined as :

$$
\tilde{y}_{j, t}=\left(1-\tau_{j}\right) y_{j, t}+z_{j, t}+\Gamma_{j, t}
$$

Substitute the government budget constraint and for consumptions from the budget constraints to get market clearing:

$$
\left(1-\alpha_{j}\right) \tilde{y}_{j, t}=\left(\alpha_{j}+\frac{\tau_{v, j, t}}{1-\tau_{v, j, t}}\right)\left[\chi_{j}\left(\beta \frac{b_{j, t+1}^{h}}{1+\rho_{j, t}}-b_{j, t}^{h}\right)+\left(1-\chi_{j}\right)\left(s_{j, t}-\beta \frac{s_{j, t+1}}{1+\rho_{j, t}}\right)\right]+\frac{1}{1-\tau_{v, j, t}}\left(f_{j, t}+\beta \frac{b_{j, t+1}^{g}}{1+\rho_{j, t}}-b_{j, t}^{g}{ }^{\prime}\right.
$$

Assuming permanent shocks on foreign demand, $\mathbb{E}_{t}\left[b_{j, t+2}^{g}\right]=b_{j, t+1}^{g}$, small shocks on spreads and $\mathbb{E}_{t}\left[\tau_{v, j, t+1}\right]=\tau_{v, j, t}$, expected market clearing at $t+1$ is:

$$
\begin{array}{r}
\left(1-\alpha_{j}+\left(\alpha_{j}+\frac{\tau_{v, j, t}}{1-\tau_{v, j, t}}\right)\left(1-\chi_{j}\right) \frac{\beta \theta \rho_{j, t}}{1-\beta \theta}\right) \mathbb{E}_{t}\left[\tilde{y}_{j, t+1}\right]= \\
(1-\beta)\left[\left(\alpha_{j}+\frac{\tau_{v, j, t}}{1-\tau_{v, j, t}}\right)\left(\left(1-\chi_{j}\right) s_{j, t+1}-\chi_{j} b_{j, t+1}^{h}\right)-\left(\frac{1}{1-\tau_{v, j, t}}\right) b_{j, t+1}^{g}\right] \\
-\beta \theta \rho_{j, t}\left[\left(\alpha_{j}+\frac{\tau_{v, j, t}}{1-\tau_{v, j, t}}\right) \chi_{j} b_{j, t+1}^{h}+\frac{b_{j, t+1}^{g}}{1-\tau_{v, j, t}}\right]+\frac{f_{j, t}}{1-\tau_{v, j, t}}
\end{array}
$$

The fiscal neutrality condition is $\Gamma_{j, t}=\tau_{v, j, t}\left[\frac{1-\alpha_{j}}{\alpha_{j}}\left(y_{j, t}-g_{j, t}\right)+\frac{1}{\alpha_{j}} \frac{f_{j, t}}{1-\tau_{v, j, t}}\right]$. 


\section{B For Online Publication: Data Appendix}

\section{B.1 Eurozone}

Most economic data for Eurozone countries (employment, population, GDP, consumption, government debt, expenditures, EU transfers...) comes from Eurostat. We use data for 11 eurozone countries from 2000 to 2012. Austria, Belgium, Germany, Spain, Finland, France, Greece, Ireland, Italy, Netherlands and Portugal. We excluded Luxembourg for which household debt data is available only starting in 2005 and other countries that joined in 2007 and later.

The data on household debt comes from the BIS which itself compiled the data from national central banks. This is debt of household and non-profit institutions serving households. Credit covers all loans and debt securities and comes from both domestic and foreign lenders. The series capture the outstanding amount of credit at the end of the reference quarter.

We call government expenditures total government expenditures net of transfers, interest payments and bank recapitalization. The data on spending on bank recapitalization comes from Eurostat. It includes interest payable, capital injections recorded as deficit-increasing (capital transfer) and calls on guarantees and is net of revenues generated by bank recapitalization (guarantee fees, interest and dividends). Transfers is the addition of direct social benefits and of social transfers in kind.

Wages and prices, equal in the model, are proxied by the average of unit labor costs and consumer prices. Both come from Eurostat and the former are defined as the ratio of labor costs to labor productivity. For exports we measure the domestic value added that is associated with final consumption in the rest of the world, which corresponds to value added based exports. We use the data from the OECD-WTO Trade in Value-Added (TiVA) initiative to measure domestic value added embodied in gross exports. Data is available only in 2000, 2005, 2008 and 2009. For missing years, we use the ratio of gross exports (from Eurostat) to value added gross exports of the nearest year and multiply this ratio by the gross exports of the missing year to obtain an approximation of value added exports of the missing years.

We use annual averages of 10 year government bond rates as long term rates. The source is OECD. For the loans rates for SMEs and deposit rates, we use ECB data. SME loans are up to one million euros. Data is missing for Belgium (2003-2005), Greece, Ireland, Italy, Portugal (2000-2002) and Portugal (2007-2010). The deposit rates have maturity of up to one year. Irish data is missing. For the other countries, it starts in 2003. For 5 year CDS we use IMF data which starts only in 2008.

The source for the TFP in figure (21) is the Conference Board.

\section{B.2 United States}

Data for the United States comes from the BEA, the Flow of Funds (FoF), and from the FRBNY Consumer Credit Panel. BEA and FoF data are standard and widely used so we do not discuss them.

The FRBNY Consumer Credit Panel is described in Lee and van der Klaauw (2012). It is a new longitudinal database with detailed information on consumer debt and credit. This panel is a random sample from consumer credit reports. It is available from 1999 onwards. Credit reporting agencies compile and maintain credit histories for all U.S. residents who have applied for or taken out a loan. Credit bureaus continuously collect information on individual consumers' debt and credit from lenders and creditors. Most individuals begin building a credit history when they first obtain and use a credit or retail card or take out a student loan, usually when they are at least 18 years of age. New immigrants with little or no credit history from their home country are often older 
Figure 21: Changes in Trend TFP Do Not Explain the Eurozone Crisis

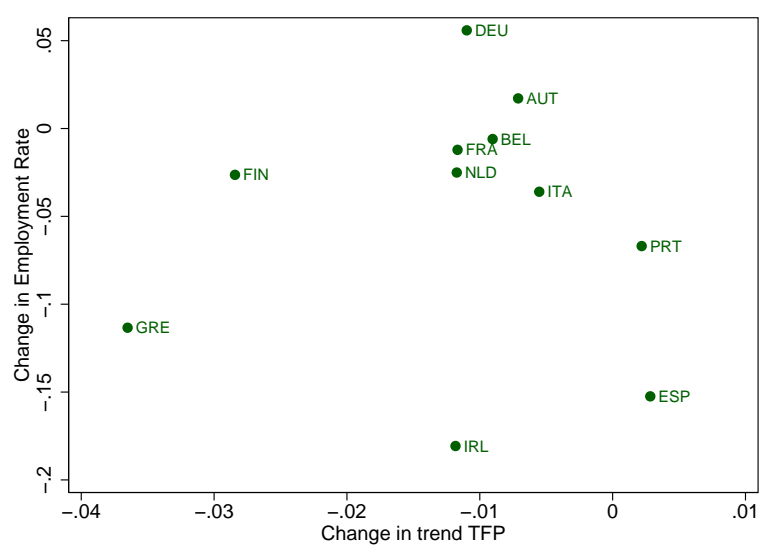

Notes: Horizontal Axis is average TFP growth during 2008-2012 minus average TFP growth during 2000-2007 (source: Conference Board). Vertical Axis is change in employment rate between 2008 and 2012.

when a credit file is first created for them. The sample design implies that the target population consists of all US residents with a credit history. In addition to most individuals younger than 18, who had little need or opportunity for credit activity, the target population excludes individuals who have never applied for or qualified for a loan.

The data at the State level is available in three data sets on the FRBNY web site:

- State level data for all States from 1999 to 2012, annual data for Q4 only.

- Selected states from 1999 to 2003, quarterly data.

- Selected states from 2003 to 2014, quarterly data.

Lee and van der Klaauw (2012) argue that household debt estimates based on the FRBNY Consumer Credit Panel are similar to estimates reported in the Board of Governors' Flow of Funds Accounts. There are differences, however. First, the household debt measures in the Flow of Funds are not based on direct data but instead are derived as residual amounts. Total mortgage debt and non-mortgage debt in the second quarter of 2010 were respectively $\$ 9.4$ and $\$ 2.3$ trillion, the comparable amounts in the FoF for the same quarter were $\$ 10.2$ and $\$ 2.4$ trillion, respectively.

Second, the FoF measure of household mortgage debt includes some mortgage debt held by nonprofit organizations (churches, universities, etc.). On the other hand, FRBNY estimates exclude some debt held by individuals without social security numbers. There may also be differences in the speed at which changes in various types of debt are recorded, where new mortgage accounts usually appear on credit reports with some delay, making some direct comparisons difficult. The comparison is shown in figure (22).

Local Fiscal Policy One potential issue is whether fiscal policy was not also active in the US. Perhaps private debt bubbles were associated with large fiscal revenues and large spending. This probably happened to some extent, but compared to the Eurozone, these effects are small (of course we are only talking about cross-sectional variation in government spending). Figure (23) shows this for two states and two countries. A regression for all the states and all the countries shows that the link between private debt and government spending was at least four times smaller in the US than in Europe. 
Figure 22: Comparison of Household Debt Measures

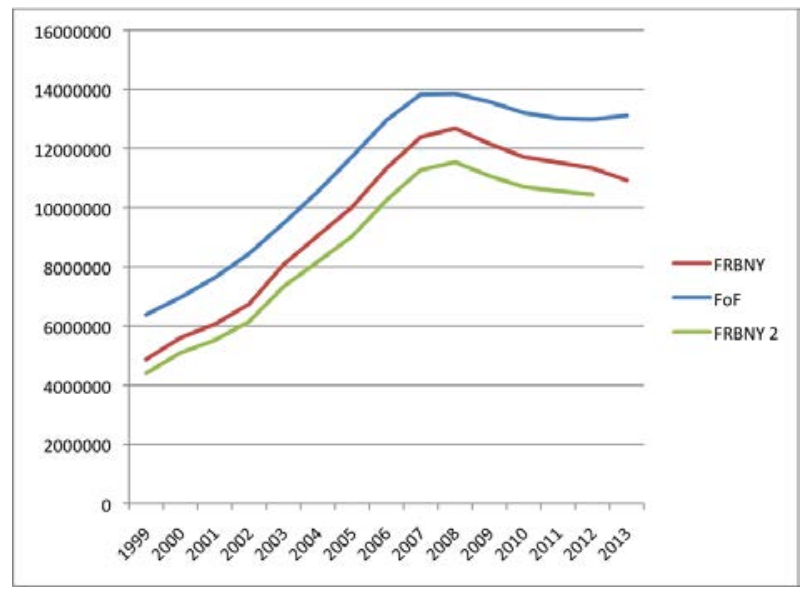

Figure 23: Government Spending

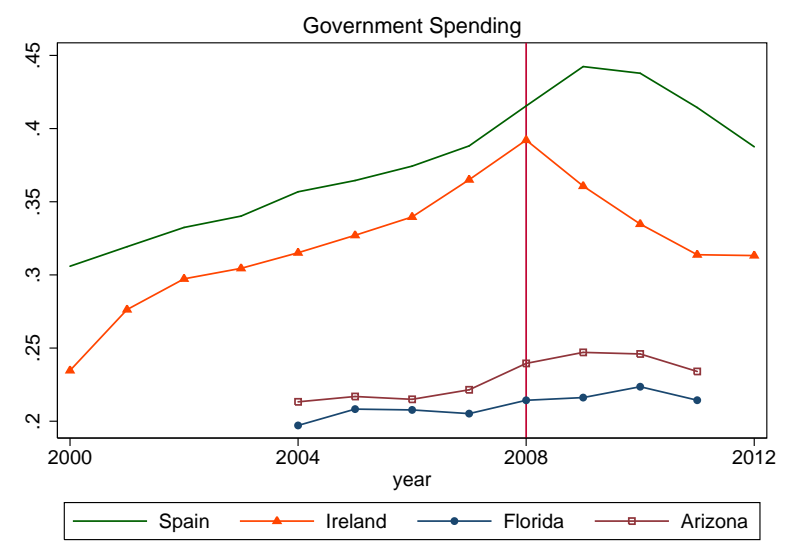

We therefore argue that the US provides a benchmark for private deleveraging without sudden stops, and with relatively neutral (cross-sectional) fiscal policy.

\section{B.3 Scaled data}

The scaled data for household and public debt, government expenditures and transfers, 10 year government bonds, foreign demand, and spreads and our scaled measure of $\rho_{j, t}$ are shown in figures (24), (25), (26) and (27) respectively. 
Figure 24: Household and Public Debt

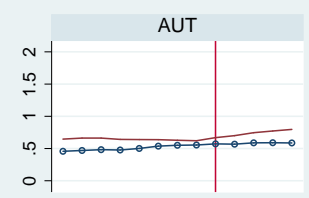

FIN

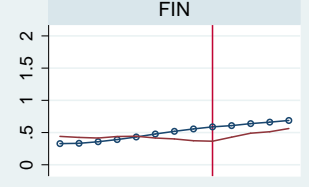

ITA

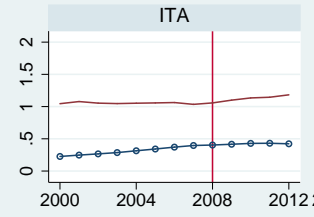

- Scaled household debt
BEL

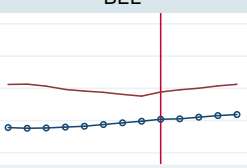

FRA

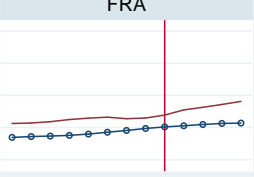

NLD

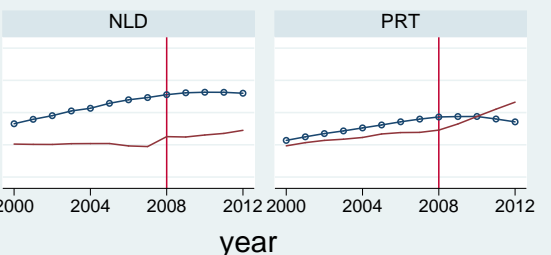

GRE

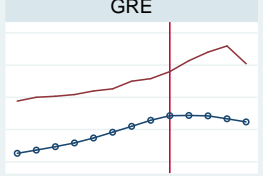

$\begin{array}{llll}2000 & 2004 & 2008 & 2012\end{array}$

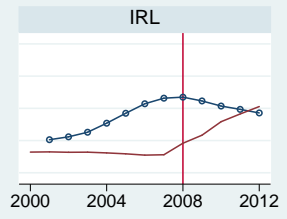

Graphs by country

Figure 25: Government Expenditures and Transfers

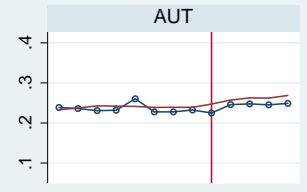

FIN

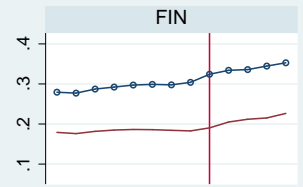

ITA
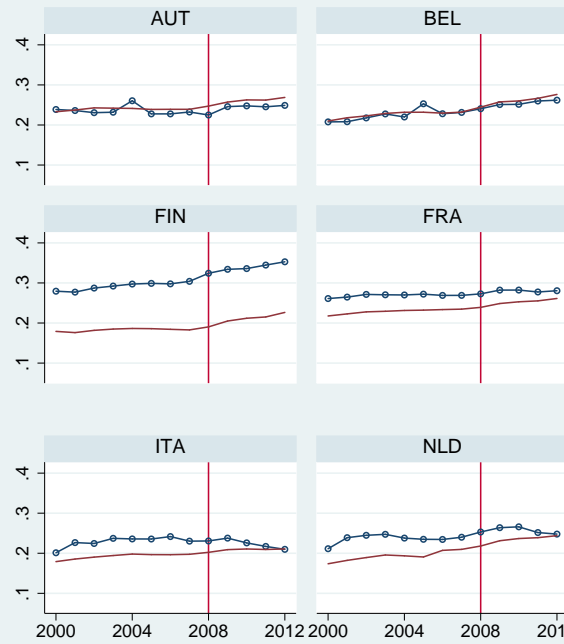

FRA

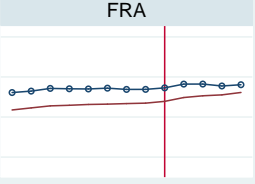

NLD

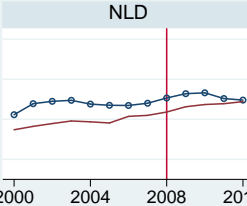

year
Scaled public debt 
Figure 26: Value Added Based Exports

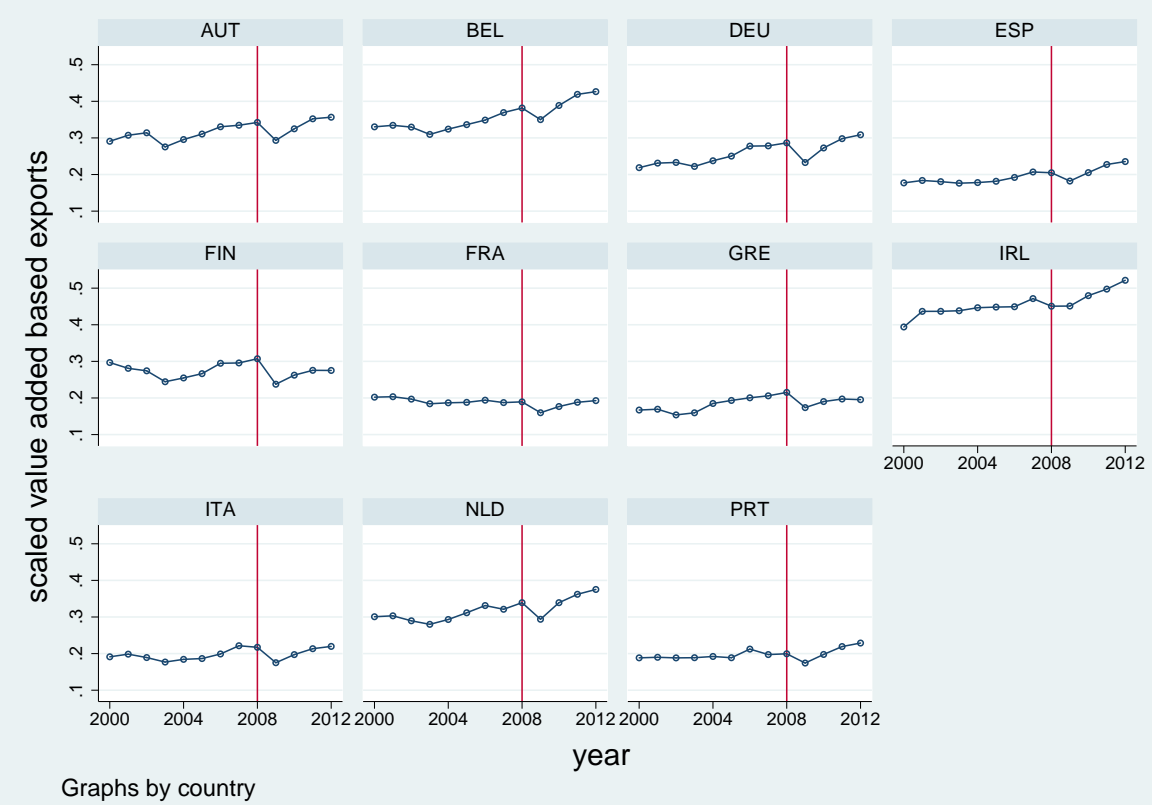

Figure 27: Spreads (10 Year Government Bonds) and $\rho_{j, t}$

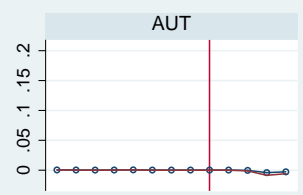

FIN

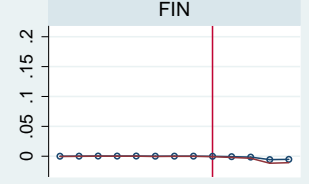

TA

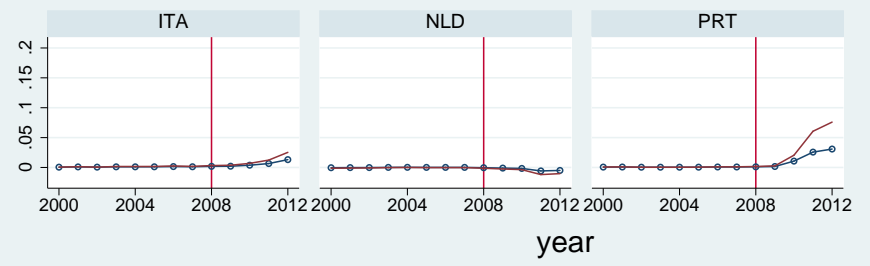

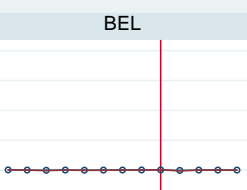

FRA

$\longrightarrow$ rho $\longrightarrow$ Spread (\%)

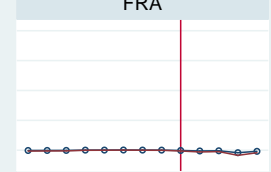

Graphs by country

DEU

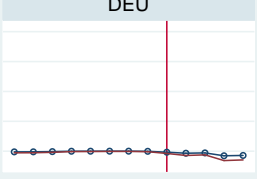

GRE
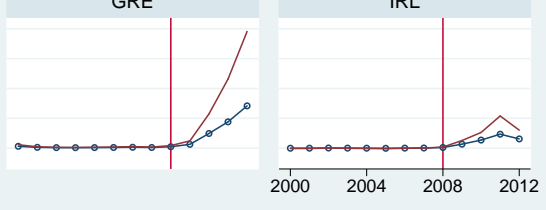

IRL 